\title{
Sovereign Default Resolution Through Maturity Extension
}

Working Paper 2017-08

Gabriel Mihalache

June 19, 2017

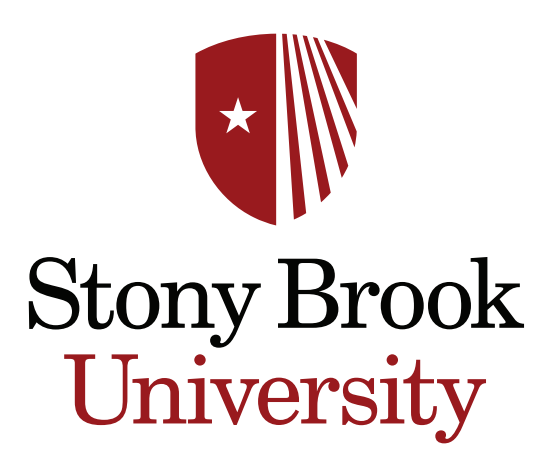




\title{
Sovereign Default Resolution Through Maturity Extension
}

\author{
Gabriel Mihalache* \\ Stony Brook University
}

June 19, 2017

\begin{abstract}
Sovereigns resolve their default status by offering bond swaps to their lenders, usually following negotiations. We model this interaction in a quantitative model of borrowing and default, and focus on its consequences for debt levels, default risk, and haircuts. The empirical literature finds that the bulk of debt relief is implemented by lengthening the maturity of debt, rather than changing face value. Countries exit renegotiations with less debt but with a greater share of long-term debt in total, compared to the maturity structure at the time of default. A standard maturity choice model, augmented with a renegotiation phase, is unable to replicate this critical feature of the data. We explain this negative result by showing an equivalence between the choice of maturity during the swap and and at issuance, in key states of the world. Introducing a demand shock solves the puzzle. We interpret this reduced-form shock in the context of the literature on political turnover risk. It captures in a parsimonious way the notion that emerging markets may elect policy-makers more prone to short-termism.
\end{abstract}

(JEL F34, G11, G15, H63)

*S617 SBS, Department of Economics, Stony Brook University, Stony Brook, NY, 11794, Email: mihalache@gmail.com Website: http://www.gmihalache.com/

Acknowledgements: I am greatly indebted to Yan Bai for her encouragement and guidance. I would like to thank George Alessandria, Manuel Amador, Cristina Arellano, Mark Bils, Yongsung Chang, Dan Lu, Yena Park, Iván Werning, and participants to the Midwest Macro Fall 2015 conference and the University of Rochester and Stony Brook University workshops for many useful suggestions and comments. I am grateful to Christoph Trebesch, Jeromin Zettelmeyer, and Tamon Asonuma, as well as to Juan Carlos Hatchondo, for sharing their data and code, respectively. 


\section{Introduction}

Governments actively manage the maturity structure of their debt over the cycle and, in particular, one key pattern is that emerging markets shorten the maturity of their issuance whenever conditions worsen, during recessions and in the run-up to debt crises. A more recent, largely empirical research program has turned to the resolution of sovereign default episodes, the debt swaps used by sovereigns to implement new terms for their lenders. It focuses on bondlevel and aggregate haircuts and their relation to debt relief, the length of market exclusion, and exit spreads. This literature stresses the importance of taking a present-value approach to haircuts, rather than considering changes in face value alone, given the importance of changes in the timing of payments (i.e. maturity) versus changes in the notional size of payments. The comprehensive account of Cruces and Trebesch [2013] concludes that maturity extension is the main mechanism for debt relief: debt swaps reduce overall indebtedness, yet a greater share of the debt takes the form of long-term bonds, compared to the composition of debt at the time of default.

We provide a quantitative-theoretic analysis of the resolution of default crises via bond swaps and the incentives that lean country to negotiate maturity extensions. To the best of our knowledge, we are the first to provide a joint, quantitative account of maturity choice both during issuance and as part of the post-default restructuring process. In so doing, we bring together separate but inherently related strands of the literature on sovereign debt. Moreover, we are able to leverage insights from previous work on maturity choice to the novel question of the maturity structure of swaps. Our model can jointly replicate the reduction of maturity induced by negative shocks as well as the maturity extension implemented by eventual negotiations and swaps.

We start by showing that a model using a mix of canonical maturity choice and renegotiation mechanisms delivers swaps inconsistent with the data, even though it matches other business cycle and debt-related facts. We explain this failure in light of an equivalence result, between the choice of maturity at the time of the swap and at issuance in particular states of the world. Allowing for a parsimonious demand shock can solve this puzzle and replicate the quantitative behavior of maturity around swap events. We interpret and discipline this shock in light of evidence on the role of political turnover risk: policy-making alternates randomly between spells of impatience, when the country is more willing to borrow, spend, and default, and patience, when fiscal consolidation is likely to be undertaken. This time-varying degree to which lack of commitment is a binding constraint on the sovereign's choices, in a manner orthogonal to the underlying fundamentals, is the key feature supporting maturity extension in equilibrium. Our result provides support to the idea that demand shocks and political economy considerations can play a significant role in quantitative accounts of external fiscal policy.

We build on the maturity choice model of Arellano and Ramanarayanan [2012], in which a risk-averse sovereign issues both short- and long-term bonds. Risk-neutral international lenders hold these bonds, so that all debt is external. The country borrows both because it is more impatient than the lenders and to smooth consumption in the face of endowment risk. The government can choose to default, i.e. suspend debt service payments. While default allows for increased consumption in the current period, it comes at the cost of temporary market 
exclusion and a reduction in endowment ${ }^{1}$. The government lacks commitment over future default or issuance decisions, it acts opportunistically, with the knowledge that it - or future governments-will act in a similar fashion. With a constant probability, a sovereign in default can regain good credit standing and return to markets but, unlike most of the literature, debt is not fully repudiated upon default. Instead, in order to return, the government must reach an agreement with its lenders and restructure its debt: it will swap the old short- and long-term bonds for new instruments and then resume payments under the new maturity structure. We use Nash bargaining, as in Yue [2010]. The Nash renegotiations will induce both a new level of debt as well as a new maturity structure. Each unit of the old bonds is assigned, based on its maturity, a fraction of the new portfolio. By allowing for a less favorable treatment for old short bonds we replicate the haircut heterogeneity in the data.

We find that the model in which the stochastic endowment is the only source of uncertainty performs well along a set of key moments, except for the change in maturity induced by the swap: systematically, the model swap has the country resume payments with short-term debt only, whereas in the data maturity is always lengthened. This puzzle motivates an additional deviation from the environment in Arellano and Ramanarayanan [2012], a role for political turnover risk, captured parsimoniously by a time-varying discount factor, a demand shock.

We'll argue that in order to understand the failure of the canonical setup and our solution, it is essential that we revisit the trade-off faced at issuance, while in good credit standing. With or without the demand shock, the model exhibits the issuance pattern in the data: as fundamentals worsen, e.g. below mean endowment draws, the country will shorten the maturity of its issuance. This result can be understood in light of the trade-off between the incentives benefits of short-term debt and the insurance, or hedging, properties of long-term debt. With short-term debt the sovereign is exposed to its own default risk in a more straightforward manner, akin to a monopolist facing a more elastic demand schedule (See Aguiar and Amador [2014]). On the other hand, the market value of long-term debt incorporates the value of the sequence of future payments, and this values moves favorably for the sovereign, since the longterm bond price is countercyclical due to changes in default risk and future issuance behavior, i.e. dilution. With worsening conditions, insurance is less appealing, relative to rolling over short-term bonds.

We leverage these insights by showing that the relative first-order condition determining the maturity of debt in our Nash swap coincides with the same condition at issuance, when there is no outstanding debt, a "fresh start." This means that in order to understand why the Nash solution sharply favors short-term debt upon exit, we must consider the borrowing behavior of a sovereign starting without any debt. We find that the governments starts accumulating debt first by borrowing short only, eventually adding long-term bonds a few years in. We argue that this is because there's no role for insurance during most of the transition path from the initial no-debt state to debt levels around the model's stochastic steady state. With low but growing debt levels, incentivizing future governments with a legacy of short debt is more appealing

\footnotetext{
${ }^{1}$ An exogenous drop in TFP or endowment upon default is a standard feature of the quantitative literature. It captures, in reduced-form, any trade or financial disruptions possibly caused by defaults. Bulow and Rogoff [1989] provide sharp results on the necessity of such output cost for sustaining debt in equilibrium, by showing that market exclusion alone is not sufficient. Mendoza and Yue [2012] model microfundations for such a cost, via a working capital channel.
} 
than providing insurance.

With a minimal alteration of the environment, a political economy motivated demand shock, we can overcome this negative result. In the model, it takes the form of a stochastic, timevarying discount factor. When policy is impatient, the government is eager to borrow and spend, and the commitment friction has more bite. With a higher discount factor though, fiscal consolidation is likely, commitment problems are less severe and maturity is longer both, at issuance and during the swap. A patient government enjoys greater insurance, even for below-average endowment levels, those that are most likely at the time of the swap. In effect, via a judicious choice of maturity, the government can secure better borrowing terms today at the expense of setting itself up for stricter "market discipline" in the future, due to rolling-over growing short-term debt.

We calibrate both specifications to Greek data, in light of the massive, recent default and swap of 2012. In our calibration we use the (mean) discount factor and the endowment penalty parameters to induce a level of debt and maturity mix similar to the data. The calibration of the discount factor shock yields new challenges and opportunities: we can increase the magnitude of the maturity extension in the swap by increasing the difference in discounting between the two types, but in so doing we generate excessive business cycle volatility. We discipline the difference between the two discount factor values and the average length of an (im)patience spell by matching the volatility of consumption relative to GDP.

The Greece 2012 swap lengthened Macaulay duration from 6.4 to 7.8 years. The model with a constant discount factor and endowment shocks only, has maturity collapsing from 8.0 years at default to 1.3 years following the swap. With a 0.08 difference between discount factors, the benchmark model has maturity increasing from 6.5 years to 7.3 years, while at the same time maintaining the relative volatility of consumption close to the 1.2 value in the data, at 1.3 .

Both specifications result in unconditional default probabilities in the $2-3 \%$ range, mean external debt to GDP levels of about 0.4 , comparable to 0.5 in our sample, and a share of short-term debt in total of about one third. In both models, swaps reduce debt to GDP by about 0.4 , compared to 0.5 in the case of Greece, so that our fit over haircuts is fairly tight.

We briefly review the relevant related literature and outline the rest of the paper.

Evidence on Sovereign Debt Swaps. Cruces and Trebesch [2013] assemble a dataset of debt swap events, including estimates for bond-level haircuts. They show that maturity extension is ubiquitous and emphasize that, as a consequence, face value haircuts will systematically bias estimates of investor losses downwards. They report evidence on the relation between haircuts and either exit spreads or the duration of market exclusion. Zettelmeyer et al. [2013] compute cash flows and bond-level haircuts for the Greece 2012 event, and thus extend the dataset in the Cruces-Trebesch paper. Sturzenegger and Zettelmeyer [2006, 2007] provide in-depth accounts of sovereign debt crises from the late '90s to the mid 2000s, including Argentina's "Mega Swap," in terms of timing, cash flow estimates, haircuts, and macroeconomic conditions. Asonuma et al. [2015] find that short-term bonds suffer greater haircuts than longer-term debt in all events studied, with some quantitative variation. They construct a model in which this feature of the data can explain the observed inversion of the yield curve. More recently, Asonuma et al. [2017] compile evidence on a large number of swaps events 
and conclude that short-term debt holders suffer larger haircuts. They provide a theoretical rationale for this output from an asset pricing point of view.

The previously discussed papers deliver valuable evidence on the swap process yet none provide a comprehensive, quantitative-theoretic account of the behavior of maturity choice both at issuance and during swaps. This is our paper's main contribution, which we take to be complementary to the evidence and intuition delivered by the existing literature.

Theoretical Framework, Long-term Debt, and Maturity Choice. Eaton and Gersovitz [1981] introduce a widely used environment featuring incomplete markets and lack of commitment, with default in equilibrium. Arellano [2008] reports quantitative results building on this framework, with one-period debt only, when calibrated to the Argentina 2002 default. In this paper we build on these seminal contributions, by addressing maturity choice (further discussed below) and the debt swap process, the more novel aspect of the project.

Hatchondo and Martinez [2009] introduce long-term debt via a decaying perpetuity bond and argue that matching the average duration of debt in the data is essential to improving the model's fit, with respect to debt levels and spreads. Chatterjee and Eyigungor [2012] prove that the bond price function is downward sloping and introduce a novel numerical method for the computation of models with long-term debt. Broner et al. [2013] document the choice of maturity at issuance and find that governments borrow short during recessions and in the run-up prior to default. Arellano and Ramanarayanan [2012] study this margin in a quantitative sovereign debt model. Their model is closest to the one studied here but it abstracts from renegotiation and recovery. Aguiar and Amador [2014] consider the role of maturity choice for deleveraging, in an environment without income or endowment risk, thereby disentangling insurance from the pricing of default risk for various maturities. Bai et al. [2015] consider debt with finite maturity and varying coupon structures. Their model can allow for a choice of back-loaded debt and finite maturity, consistent with the data but impossible under the decaying perpetuity functional form widely used in the literature. Sánchez et al. [2015] allow for exogenous maturity extension and fixed recovery in an environment with finite maturity. Hatchondo et al. [2015] evaluate the role of dilution in discouraging emerging markets from issuing longer-term debt and covenants/seniority rules meant to mitigate this effect.

Recovery and Haircuts. Yue [2010] allows for positive, endogenous recovery rates by having the sovereign negotiate with its lenders via generalized Nash bargaining, in a setting with oneperiod debt only. Pitchford and Wright [2012] provide a game-theoretic account of the duration of renegotiations, eventual recovery, and holdout or free-riding incentives for lenders. Bai and Zhang [2012] rationalize the observed change in the duration of renegotiations, going from the syndicated bank loans regime of the ' 80 s to the eventual predominance of publicly-traded bonds, via information revelation about lenders' valuation in secondary markets. Hatchondo et al. [2014] consider the bilateral benefits from voluntary debt exchanges, which reduce debt overhang and potentially preempt default. Aguiar and Amador [2014, Section 5] characterizes the choice of maturity for a one-time debt restructuring, via bargaining. In their setting, with outside option but without endowment shocks, efficiency prescribes a conversion of all debt into one-period bonds. These papers' models are silent on the maturity structure of debt, prior to and following the swap, due to the assumption of one-period debt.

To the best of our knowledge, our paper is the fist to consider maturity choice as well as 
recovery/haircuts in a quantitative-theoretic setting. In so doing, we bring together the two previously discussed strands of the literature and expand the study of debt maturity to swap events.

Political Economy Frictions. Sachs [1989] and Dornbusch and Edwards [1991] discuss the "populist policy cycle" of Latin America. Policy alternates between a more short-sighted stance, with higher inflation, redistributive measures, and increased public borrowing and spending, and a consolidation stance, akin to "austerity." Cuadra and Sapriza [2008] rationalize the observed relation between policymakers' length of tenure, political stability, and sovereign spread and default rates. Hatchondo et al. [2009] introduce political turn-over risk in a sovereign default model with one-period debt and show that this additional source of uncertainty can weaken the model's excessive comovement between spreads and economic fundamentals. Aguiar and Amador [2011] find that political turnover and incumbents' preference for immediate spending will alter the convergence properties of an otherwise canonical growth model. A common theme of this research is that political frictions could be captures in reduced-form as changes in the pattern of discounting, i.e. a policy-maker effectively more impatience than the representative household, or hyperbolic discounting.

In contrast, in this paper we consider a parsimonious discount factor shock only, that we interpret in light of the results in this literature. A natural, future extension of the work presented here would include a full political economy environment along the lines of Cuadra and Sapriza [2008]. We conjecture that the quantitative properties of the model would be largely unchanged.

The rest of the paper proceeds as follows. Section 2 documents salient features of recently sovereign debt swaps. We emphasize that these involve what is commonly called a "maturity extension." In section 3 we argue that a standard maturity choice model augmented with a Nash renegotiation and recovery mechanism is unable to replicate the change of maturity from observed swaps. Close inspection of key equilibrium conditions provides insight into this failure of the benchmark environment. Introducing a reduced-form political economy friction can solve the puzzle and bridge the gap between data and model. Section 4 documents the calibration and quantitative properties of the model, under both our preferred, benchmark specification and the one with an endowment shock only, the version closest to the existing literature. Section 5 concludes.

\section{Evidence on Debt Swaps}

This section draws on the evidence reported by Sturzenegger and Zettelmeyer [2006, 2007], Cruces and Trebesch [2013], Zettelmeyer et al. [2013], and Asonuma et al. [2015] in order to identify key features of sovereign debt swaps, with an emphasis on the recent Greece 2012 episode. Two stylized facts stand out. First, the swaps implement a lengthening of maturity. In their extensive study of sovereign debt haircuts, Cruces and Trebesch [2013] report that "maturity extensions are a crucial component of overall debt relief" and that 123 of the 180 episodes in their dataset feature debt rescheduling only, as opposed to reduction in face value. Following such swaps, the mix of short-to-long-term debt is tilted toward longer-term 
obligations, i.e. the cash flow of the new bonds is more back-loaded than the one the country was scheduled to pay prior to default. Second, the old bonds receive substantially different haircuts, as a function of their outstanding maturity. It is not uncommon for short-bonds to be subjected to twice or more the haircut suffered by long-term bonds, in the systematic evidence presented by Cruces and Trebesch [2013] and, more recently, by Asonuma et al. [2017].

Greece 2012. In April 2010, following worsening real and financial conditions, Greece essentially loses market access. By April 2012, a debt swap of unprecedented scope and magnitude is implemented, with Troika ${ }^{2}$ support and via negotiations with a group of 12 major banks, representing the bulk of lenders. Later that year an extensive buy-back program leads to an overall reduction of Greek debt in private hands of over $87 \%$. Zettelmeyer et al. [2013] and Reinhart and Trebesch [2015] provide background.

The evidence reported below and used to discipline the quantitative exercise is restricted to the March/April swap alone. Figure 1 plots the payments schedule by the pre-default, "before" bonds versus those of the "after" bonds issued as part of the Greek swap deal, in billions of Euros. The swap led to a sharp reduction in payments due in the short-term, in 2012 itself but also subsequent years, counterbalanced by a steady stream of increased payments $15+$ years out. The risk-free Macaulay duration is lengthened from 6.4 to 7.8 years. The growth rate of payments ${ }^{3}$ goes from roughly $-15 \%$ to about $-5 \%$.

In addition to the bond data, Figure 8 in Appendix $C$ includes scheduled payments for official loans, e.g. IMF loans and programs, by using the Debt Distribution (DDIS) service of Bloomberg [2015]. These estimates are only available for a select subset of countries and for recent periods only. The figure shows loan and bond (principal only) flows at four points in time: prior to the swap (2011 Q1), around the March/April 2012 exchange (2012 Q1), after the end of 2012 buyback (2012 Q4), and the start of the following year (2013 Q1). The pattern of maturity extension is robust to the inclusion of these additional, official liabilities. The back-loading pattern found for the Greece 2012 event is also apparent for other bondbased swaps, Pakistan 1999, Ecuador and Russia 2000, and Argentina 2005, as shown in Figure 9 in Appendix C. The scheduled debt service is systematically reduced for the upcoming 3-5 years following the swap.

Cruces and Trebesch [2013] argue that maturity extensions are generally preferred to reductions in face value, as a way of lowering indebtedness and avoiding costly debt service payments in the short-run. This motivated them to emphasize a present-value approach when constructing their haircut dataset. Figure 2 plots the haircut applied to each bond that was exchanged against their original maturity date. The size of the bubble is proportional to each bond's principal.

\footnotetext{
2"Troika" is the informal name used for the European Commission (EC), the European Central Bank (ECB), and the International Monetary Fund (IMF), especially in relation to their negotiations and support for European governments during the post-2009 European Debt Crisis.

${ }^{3}$ Bai et al. [2015] argue that the growth rate of payments (defined as the slope of the log cash flow schedule) is an informative measure for characterizing the choice of borrowing terms at issuance. In particular, a steeper cash flow makes debt more front-loaded, shorter-term in present value, even for a fixed maturity. They find that, as fundamentals worsen, sovereigns decrease maturity and increase back-loading, flattening the stream of payments. The change in the slope partially mitigates the reduction of maturity, leading to a less than proportional change in Macaulay duration.
} 

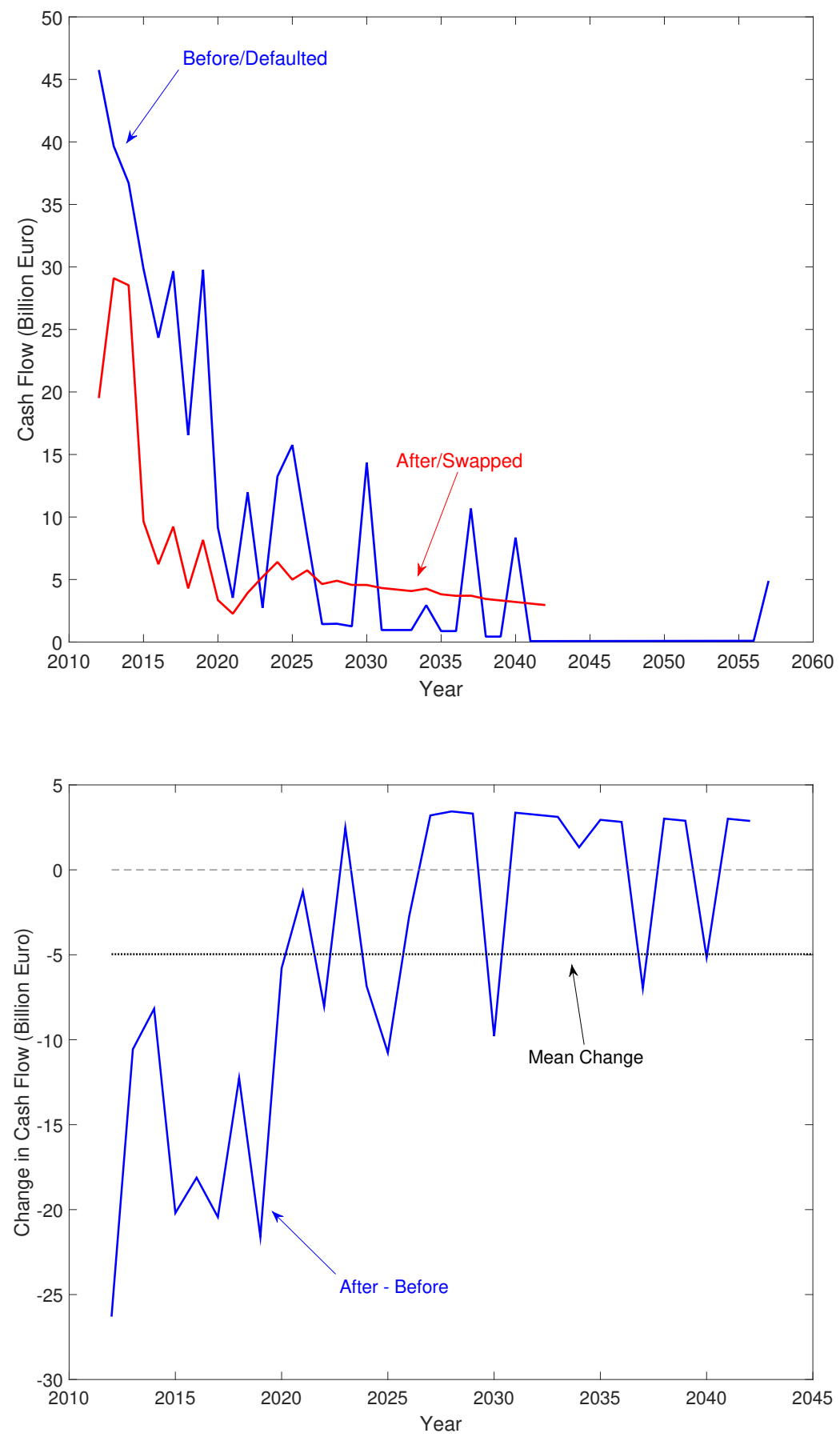

Figure 1: Cash flows, before and after swap, and difference, for Greece April/May 2012 event. Source: Zettelmeyer et al. [2013] and author's calculations. 


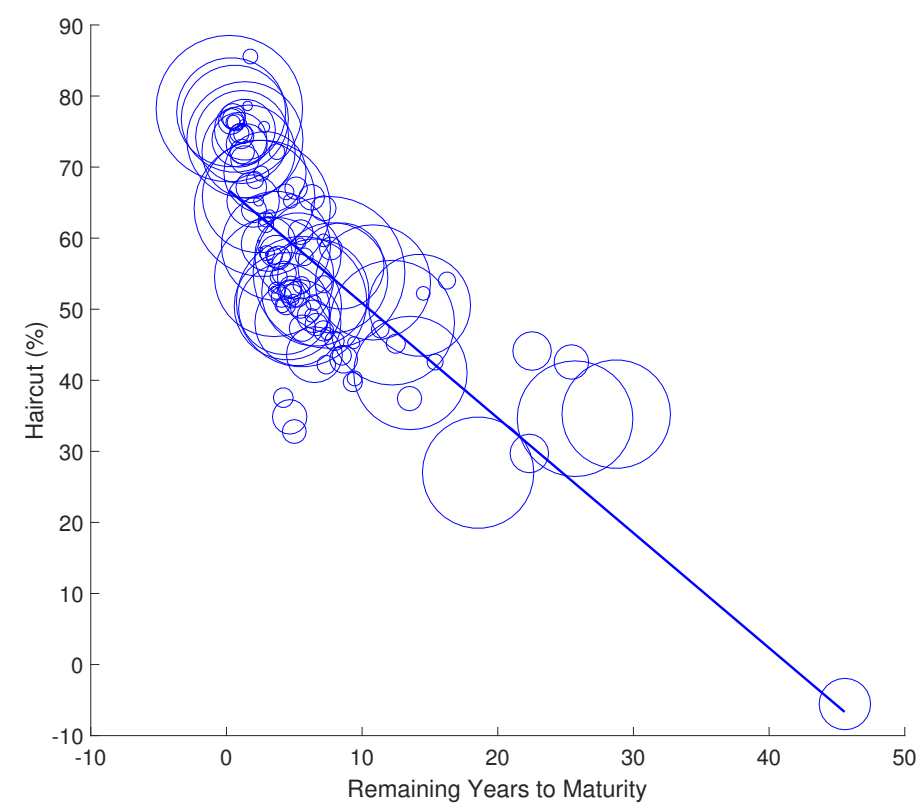

Figure 2: Bond-level haircuts, for Greece April/May 2012 event. Bubble size is proportional to principal. Source: Zettelmeyer et al. [2013]

Concerning haircuts, two points are noteworthy: first, debt relief is substantial. This is in line with the general time trend towards larger haircuts as exhibited in Figure 1 of Cruces and Trebesch [2013, p. 93]. The overall haircut for Greece 2012 was about $70 \%$, or, equivalently, a $30 \%$ recovery rate. The second salient feature of the data is that haircuts are heterogeneous across outstanding maturities. Bonds set to mature within a few years were subjected to a haircut of close to $80 \%$ while long-term bonds fared much better, with haircuts as low as $40 \%$. The experience of lenders during the Ecuador and Russia 2000 exchanges were comparable in this regard. Long-term bond holders were able to recover as much as twice compared to bonds maturing within a year or two. Asonuma et al. [2015, 2017] estimate of haircuts by maturity for a comprehensive list default and renegotiation events. They conclude that relatively worse outcomes for shorter-term debt is a robust finding. albeit with some quantitative variation across documented cases.

In the case of Greece, unequal haircuts were the result of the "one size fits all" exchange offer. All bond holders were offered shares of same bundle of new bonds, as a function of the principal owed alone, independent of other bond characteristics and in particular of years to maturity. Any haircut estimation procedure which accounts for the timing of payments via discounting will impute a larger haircut to bonds maturing sooner. Zettelmeyer et al. [2013] cite sources claiming that a desire for expediency on the part of the government motivated the choice of the "one size fits all" format, which was seen as more straightforward and transparent than a separate exchange offer for each instrument.

\footnotetext{
${ }^{4}$ See section 3.3 of Zettelmeyer et al. [2013] for examples of other swaps using this format.
} 

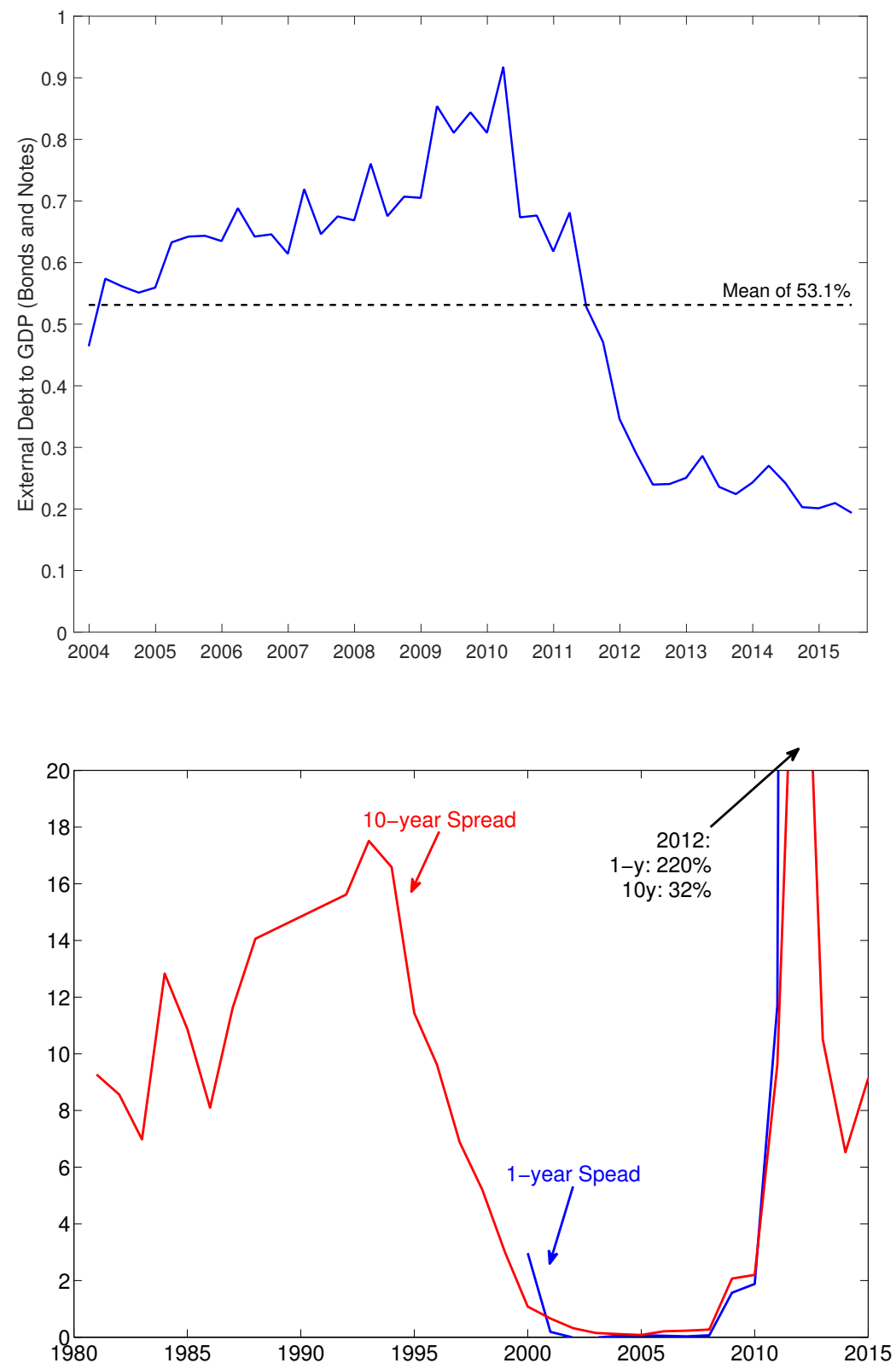

Figure 3: Greece. External debt to GDP, bonds and notes only, and 1-year and 10-year spreads (over German bonds). Source: Global Financial Data [2015]. 


\section{Model}

We develop a quantitative sovereign default model with a choice of maturity both at issuance and as part of the post-default debt swap process. We find that a version of the model subject to stochastic endowment shocks alone is unable to generate the maturity extension observed in the data. We then allow for a secondary source of uncertainty and report favorable results under this specification: we introduce political turnover risk in the spirit of Cuadra and Sapriza [2008], but in a more reduced-form. We start by laying out the model environment and the bond structure.

There are two types of agents: a risk-averse sovereign and a continuum of competitive, risk-neutral international lenders. In the tradition of Eaton and Gersovitz [1981], markets are incomplete in that the sovereign can borrow by issuing state-uncontingent instruments only, under lack of commitment. In any period, the sovereign can choose not to service its outstanding debt, in which case it enters a default state to be described below. Finally, market access is eventually regained following negotiations of a debt swap. We compare the mix of short- and long-term debt prior to default with the one resulting from the swap.

\subsection{Bonds: Maturity and Payment Schedule}

The sovereign can issue long-term bonds as in Hatchondo and Martinez [2009] and Arellano and Ramanarayanan [2012], with a choice of two maturities, Short and Long. A unit of a bond of maturity $i \in\{S, L\}$ issued this period schedules an infinite stream of debt service payments given by

$$
\kappa_{i},\left(1-\delta_{i}\right) \kappa_{i},\left(1-\delta_{i}\right)^{2} \kappa_{i},\left(1-\delta_{i}\right)^{3} \kappa_{i}, \ldots
$$

starting next period, where $\kappa_{S}$ and $\kappa_{L}$ are scaling parameters and the short term bond has a faster decay rate than the long term bond, $\delta_{S}>\delta_{L}$. Let $r$ be the risk-free interest rate at which lenders can borrow or lend internationally, assumed constant throughout. Then, the risk-free price for bond of maturity $i$ is

$$
q_{i}^{\text {rf }}=\kappa_{i} \sum_{\tau=0}^{\infty}(1+r)^{-(1+\tau)}\left(1-\delta_{i}\right)^{\tau}=\frac{\kappa_{i}}{\delta_{i}+r}
$$

and the risk-free Macaulay [1938] duration is

$$
D_{i}=\frac{1}{q_{i}^{\text {rf }}} \sum_{\tau=0}^{\infty}(1+\tau)(1+r)^{-(1+\tau)}\left(1-\delta_{i}\right)^{\tau} \kappa_{i}^{\tau}=\frac{1+r}{\delta_{i}+r} .
$$

We normalize the risk-free bond prices for both maturities to unity, $q_{i}^{\text {rf }}=1$, by setting $\kappa_{i}=$ $\delta_{i}+r$. This leaves each bond's duration unchanged. For a portfolio consisting of $b_{S}$ units of 
the short bond and $b_{L}$ units of the long bond, the Macaulay duration can be computed as

$$
\begin{aligned}
D\left(b_{S}, b_{L}\right) & =\frac{1}{a_{S}^{\text {rf }} b_{S}+q_{L}^{\text {rf }} b_{L}} \sum_{\tau=0}^{\infty}(1+\tau)(1+r)^{-(1+\tau)}\left[\left(1-\delta_{S}\right)^{\tau} \kappa_{S}^{\tau} b_{S}+\left(1-\delta_{L}\right)^{\tau} \kappa_{L}^{\tau} b_{L}\right] \\
& =\frac{b_{S}}{b_{S}+b_{L}} D_{S}+\frac{b_{L}}{b_{S}+b_{L}} D_{L}=D_{S}+\left(D_{L}-D_{S}\right) \frac{b_{L}}{b_{S}+b_{L}} .
\end{aligned}
$$

Such a bond, trading a market price $q_{i}$ carries a yield-to-maturity spread $s_{i}$ implicitly defined by

$$
q_{i}=\frac{\kappa_{i}}{\left(r+s_{i}\right)+\delta_{i}} \Rightarrow s_{i}=\left(\frac{1}{q_{i}}-1\right) \kappa_{i}
$$

\subsection{The Sovereign}

The sovereign starts each period with $b_{S}$ and $b_{L}$ outstanding units of the short and long bond respectively and an endowment realization $y$, drawn from a Markov process with support $\mathbb{Y}$, and a discount factor $\beta$ governed by a Markov chain with support $\mathbb{B}$. The state is given by the tuple $\left\langle\beta, y, b_{S}, b_{L}\right\rangle \in \mathbb{B} \times \mathbb{Y} \times \mathbb{R} \times \mathbb{R}$. The government may decide to exert its default option and receive state-contingent value $V^{d}$. Alternatively, it can continue making debt service payments and achieve value $V^{p}$, in which case we say that the country is "in good credit standing."

$$
V\left(\beta, y, b_{S}, b_{L}\right)=\max _{d \in\{0,1\}} d V^{d}\left(\beta, y, b_{S}, b_{L}\right)+(1-d) V^{p}\left(\beta, y, b_{S}, b_{L}\right)
$$

In each period with good credit standing, the sovereign will auction $\ell_{S}$ units of the short bond and $\ell_{L}$ units of the long bond. Whenever $\ell_{i}<0$ the country is retiring, buying back some of its outstanding bonds. The stock of debt at the start of the period $\left\langle b_{S}, b_{L}\right\rangle$ and the new issuance $\left\langle\ell_{S}, \ell_{L}\right\rangle$ determine the stock of debt at the start of the next period $\left\langle b_{S}^{\prime}, b_{L}^{\prime}\right\rangle$ via the stock-flow identity $b_{i}^{\prime}=\left(1-\delta_{i}\right) b_{i}+\ell_{i}$, so that we can think of the government as either choosing issuance or the new debt stock.

The sovereign makes debt service payments and chooses consumption together with new issuance, subject to the budget constraint

$$
c+\kappa_{S} b_{S}+\kappa_{L} b_{L}=y+q_{S}\left(y, b_{S}^{\prime}, b_{L}^{\prime}\right) \ell_{S}+q_{L}\left(y, b_{S}^{\prime}, b_{L}^{\prime}\right) \ell_{L},
$$

taking the bond price schedules $q_{S}$ and $q_{L}$ as given. Net exports are given by $y-c$.

The value under debt service satisfies

$$
\begin{aligned}
& V^{p}\left(\beta, y, b_{S}, b_{L}\right)=\max _{c, b_{S}^{\prime}, b_{L}^{\prime}} u(c)+\beta \mathbb{E} V\left(\beta^{\prime}, y^{\prime}, b_{S}^{\prime}, b_{L}^{\prime}\right) \\
& \text { s.t. } b_{i}^{\prime}=\left(1-\delta_{i}\right) b_{i}+\ell_{i}, \text { for all } i \in\{S, L\} \\
& \quad \text { and }(6)
\end{aligned}
$$

Throughout, the operator $\mathbb{E}$ refers to the expectation conditional on the current realization of the endowment $y$ and discount factor $\beta$, i.e.

$$
\mathbb{E} X\left(\beta^{\prime}, y^{\prime}\right)=\int_{\mathbb{B} \times \mathbb{Y}} X\left(\beta^{\prime}, y^{\prime}\right) d F\left(\beta^{\prime}, y^{\prime} \mid \beta, y\right) \text {. }
$$


We note one difference between our $\beta$ shock and the mechanism in Cuadra and Sapriza [2008] or Hatchondo et al. [2009]: in our environment the policy-maker chooses how much to borrow this period, at which maturity, knowing that it might change its policy stance in the future (draw a new $\beta^{\prime} \neq \beta$ ), while the parties in their setups always have the same $\beta$ so that whenever they are not in power they will disapprove of the borrowing choices of the incumbent. A party in power has an incentive to alter borrowing in an attempt to mitigate the welfare loss from losing power. In their setup, for example, a "fiscally conservative" government would benefit from constraining a potential impatient successor, via a legacy of mostly short-term debt.

\subsection{Default and Debt Renegotiation}

The choice of default triggers an endowment penalty and temporary exclusion from world markets. For an endowment realization of $y, \mathrm{GDP}$ is $h(y) \leq y$ whenever the sovereign is in default. Furthermore, the country is in autarky, $c=h(y)$. Then, each period, the country will successfully reach an agreement with its creditors and reenter markets with probability $\eta .^{5}$ The government and the bond holders agree to swap the defaulted debt $\left\langle b_{S}, b_{L}\right\rangle$ for a new portfolio $\left\langle\gamma_{S}, \gamma_{L}\right\rangle$. We assume that the swap takes one period so that the sovereign remains in autarky in the current period, while negotiating, and then starts making payments on the new debt in the following period. This timing assumption will better contrast the choice of maturity at issuance and during the swap, in terms of the first-order conditions studied in section 3.6. We model the debt swap negotiation using the Generalized Nash Bargaining. We assume that all creditors are represented by a single committee, aiming to maximize the market value of the new bonds. We discuss shortly the allocation of the new bonds to the old bond holders. Appendix $B$ shows that the same bargaining outcome can be achieved if we instead allow short and long debt holders to form separate committees, with different bargaining powers. The result reflects the homogeneity of lenders in terms of attitude towards risk and outside options. We set the threat point for the government to the value it can achieve in permanent autarky subject to the output loss penalty. The corresponding threat point for the creditors is 0 , i.e. no recovery.

$$
V^{\text {aut }}(\beta, y)=u(h(y))+\beta \mathbb{E} V^{\text {aut }}\left(\beta^{\prime}, y^{\prime}\right)
$$

Given out timing assumption, the sovereign's surplus from rejoining markets next period, with outstanding bonds $\left\langle\gamma_{S}, \gamma_{L}\right\rangle$ is

$$
\begin{aligned}
\Delta_{\text {Sov }}\left(\beta, y, \gamma_{S}, \gamma_{L}\right) & =\left\{u(h(y))+\beta \mathbb{E} V\left(\beta^{\prime}, y^{\prime}, \gamma_{S}, \gamma_{L}\right)\right\}-V^{\text {aut }}(\beta, y) \\
& =\beta \mathbb{E}\left[V\left(\beta^{\prime}, y^{\prime}, \gamma_{S}, \gamma_{L}\right)-V^{\text {aut }}\left(\beta^{\prime}, y^{\prime}\right)\right] .
\end{aligned}
$$

The surplus of international creditors is the market value of the new debt:

$$
\Delta_{\text {Cre }}\left(\beta, y, \gamma_{S}, \gamma_{L}\right)=q_{S}\left(\beta, y, \gamma_{S}, \gamma_{L}\right) \gamma_{S}+q_{L}\left(\beta, y, \gamma_{S}, \gamma_{L}\right) \gamma_{L}
$$

\footnotetext{
${ }^{5}$ Mendoza and Yue [2012] endogenize the output loss due to default. Bai and Zhang [2012] and Pitchford and Wright [2012] endogenize the length of market exclusion and negotiation. Here we abstract from these features in order to better focus on the swap terms, our main objective.
} 
The Nash bargain for a sovereign that defaulted with outstanding debt $\left\langle b_{S}, b_{L}\right\rangle$, a current endowment realization of $y$, and a discount factor $\beta$ is

$$
\begin{aligned}
\underset{\gamma_{S}, \gamma_{L}}{\operatorname{argmax}}[ & \left.\Delta_{\mathrm{Sov}}\left(\beta, y, \gamma_{S}, \gamma_{L}\right)\right]^{\alpha}\left[\Delta_{\mathrm{Cre}}\left(\beta, y, \gamma_{S}, \gamma_{L}\right)\right]^{1-\alpha} \\
\text { s.t. } & \Delta_{\text {Sov }} \geq 0 \text { and } \Delta_{\text {Cre }} \geq 0
\end{aligned}
$$

where $\alpha$ is the sovereign's bargaining power parameter.

Note that the defaulted debt portfolio $\left(b_{S}, b_{L}\right)$ does not enter the Nash program. $\gamma_{S}$ and $\gamma_{L}$ are functions of the endowment realization $y$ and discount factor $\beta$ alone. This further implies that the value of default is independent of the defaulted portfolio. This is Yue [2010]'s "bygones are bygones" result. The Nash solution maximizes and splits the surplus, an inherently forwardlooking object. The value created by resuming market access and lifting of the output costs is inherently independent of pre-default debt levels. One potentially unpalatable consequence is that we cannot rule out, a priori, recovery rates in excess of $100 \%$, if the swap takes places during periods with high enough endowment draws. In future work we plan to explore the consequences of rendering the bargaining outcome sensitive to pre-default debt, by employing alternative setups (e.g. Kalai and Smorodinsky [1975]) or by allowing either parties' outside option to depends on the pre-default portfolio.

The new bonds are allocated to the old bond holders using the following rule, motivated by the evidence presented in Section 2 on "one-size-fits-all" swaps: the old short bonds receive a share

$$
\mathcal{S}_{i}=\frac{\mu_{S} b_{S}}{\mu_{S} b_{S}+\mu_{L} b_{L}}
$$

of the new portfolio, both maturities, while the rest are assigned to the old long bonds. On a per-unit basis, each old unit of the short bond is swapped for $\mathcal{S}_{i} \gamma_{S} / b_{S}$ new units of short and $\mathcal{S}_{i} \gamma_{L} / b_{S}$ units of long. Normalize $\mu_{L}=1$. Then, $\mu_{S}$ is a parameter controlling the "weight" of a short bond units relative to long units. In the calibration section below we explore its quantitative role. Here, we focus on its role in determining the recovery or haircut rates. We define the aggregate haircut as the percent change in present, face value:

$$
H_{\text {Agg }}=1-\frac{q_{S}^{\mathrm{rf}} \gamma_{S}+q_{L}^{\mathrm{rf}} \gamma_{L}}{q_{S}^{\mathrm{rf}} b_{S}+q_{L}^{\mathrm{rf}} b_{L}}=1-\frac{\gamma_{S}+\gamma_{L}}{b_{S}+b_{L}}
$$

Alternatively, we can account for the default risk going forward and define a market-value haircut using the exit spread as

$$
H_{\mathrm{Agg}}^{\mathrm{Mrkt}}=1-\frac{q_{S}\left(\beta, y, \gamma_{S}, \gamma_{L}\right) \gamma_{S}+q_{L}\left(\beta, y, \gamma_{S}, \gamma_{L}\right) \gamma_{L}}{q_{S}\left(\beta, y, \gamma_{S}, \gamma_{L}\right) b_{S}+q_{L}\left(\beta, y, \gamma_{S}, \gamma_{L}\right) b_{L}}
$$

Similarly, we define the haircut applied to maturity $i \in\{S, L\}$ as

$$
H_{i}=1-\mathcal{S}_{i} \frac{\left(q_{S}^{\mathrm{rf}} \gamma_{S}+q_{L}^{\mathrm{rf}} \gamma_{L}\right)}{q_{i}^{\mathrm{rf}} b_{i}}=1-\mathcal{S}_{i} \frac{\left(\gamma_{S}+\gamma_{L}\right)}{b_{i}}
$$

and the market value version

$$
H_{i}^{\mathrm{Mrkt}}=1-\mathcal{S}_{i} \frac{\left(q_{S}\left(\beta, y, \gamma_{S}, \gamma_{L}\right) \gamma_{S}+q_{L}\left(\beta, y, \gamma_{S}, \gamma_{L}\right) \gamma_{L}\right)}{q_{i}\left(\beta, y, \gamma_{S}, \gamma_{L}\right) b_{i}}
$$


Finally, under the above timing and bargaining assumptions, the value of default is

$$
\begin{aligned}
V^{d}\left(\beta, y, b_{S}, b_{L}\right)=u & (h(y))+\beta \mathbb{E}\{ \\
& (1-\eta) V^{d}\left(\beta^{\prime}, y^{\prime}, b_{S}, b_{L}\right) \\
& \left.+\eta\left[u\left(h\left(y^{\prime}\right)\right)+\beta^{\prime} V\left(\beta^{\prime \prime}, y^{\prime \prime}, \gamma_{S}, \gamma_{L}\right)\right]\right\} .
\end{aligned}
$$

\subsection{Bond Prices and Recovery Values}

We assume international investors are competitive, risk-neutral, and that they can borrow or lend freely at a constant risk-free rate ${ }^{6}$. Then, in order for them to break even, the bond price for maturity $i$ must satisfy

$$
\begin{aligned}
q_{i}\left(\beta, y, b_{S}^{\prime}, b_{L}^{\prime}\right)=\frac{1}{1+r} & \mathbb{E}\left\{d\left(\beta^{\prime}, y^{\prime}, b_{S}^{\prime}, b_{L}^{\prime}\right) \chi_{i}\left(\beta^{\prime}, y^{\prime}, b_{S}^{\prime}, b_{L}^{\prime}\right)\right. \\
& \left.+\left(1-d\left(\beta^{\prime}, y^{\prime}, b_{S}^{\prime}, b_{L}^{\prime}\right)\right)\left(\kappa_{i}+\left(1-\delta_{i}\right) q_{i}\left(\beta^{\prime}, y^{\prime}, b_{S}^{\prime \prime}, b_{L}^{\prime \prime}\right)\right)\right\}
\end{aligned}
$$

where $b_{i}^{\prime \prime}$ is the stock of maturity $i$ that the sovereign will choose next period, conditional on not defaulting, $d$ is the sovereign's default policy function and $\chi$ is the expected recovery rate, implied by the debt swap procedure described in the previous section:

$$
\chi_{i}\left(\beta, y, b_{S}^{\prime}, b_{L}^{\prime}\right)=\frac{1}{1+r} \mathbb{E}\left\{(1-\eta) \chi_{i}\left(\beta^{\prime}, y^{\prime}, b_{S}^{\prime}, b_{L}^{\prime}\right)+\eta \mathcal{S}_{i} \frac{\Delta_{\mathrm{Cre}}\left(\beta^{\prime}, y^{\prime}, \gamma_{S}, \gamma_{L}\right)}{b_{S}}\right\}
$$

where $\gamma_{i}$ is the the new debt of maturity $i$ resulting from negotiation in state $\left\langle\beta^{\prime}, y^{\prime}, b_{S}^{\prime}, b_{L}^{\prime}\right\rangle$.

\subsection{Equilibrium}

Let $\mathbb{S}=\mathbb{B} \times \mathbb{Y} \times \mathbb{R} \times \mathbb{R}$ denote the state. A Recursive Markov Equilibrium consists of

(a) Value functions $V, V^{d}, V^{p}: \mathbb{S} \rightarrow \mathbb{R}$,

(b) Default $d: \mathbb{S} \rightarrow\{0,1\}$ and borrowing policies $\ell_{S}, \ell_{L}: \mathbb{S} \rightarrow \mathbb{R}$,

(c) Nash solution $\gamma_{S}, \gamma_{L}: \mathbb{S} \rightarrow \mathbb{R}$,

(d) Bond prices and recovery rates $q_{S}, q_{L}, \chi_{S}, \chi_{L}: \mathbb{S} \rightarrow[0,1]$

\footnotetext{
${ }^{6}$ Albeit a common benchmark, this approach to modeling the lenders' problem is a potentially strong restriction on the environment. Under these assumptions, lenders care only about the actuarially-fair present-value of cash flows, including during renegotiations. This rules out any role for lenders' "preferences" over the maturity composition of debt, as would emerge if, for example, lenders' are constrained by their balance sheets and these record sovereign debt at face value. Indeed, a preference for maturity extension over face value haircuts would be one plausible interpretation of lenders' choices when faced with a menu of haircuts, during Argentina's 2005 swap. Here we use the baseline case for the lenders and explore the incentives faced by the sovereign, while acknowledging the possibility of an alternative account of these restructuring proceedings, based on lenders' incentives. Regarding attitudes towards risk, Lizarazo [2013] studies lender risk-aversion in a standard environment, while Arellano and Ramanarayanan [2012] study yield curves in a setting with a richer pricing kernel.
} 
such that

1. The value functions satisfy equations (5), (7), and (17),

2. The sovereign's policies solve programs (5) and (7),

3. The Nash solution solves the program (12),

4. International investors break even, so that the bond prices satisfy (18) and (19).

\subsection{First-Order Characterization}

Following Arellano and Ramanarayanan [2012, section III.C] we study a first-order characterization of the optimal maturity structure at issuance and following debt renegotiation. Assume $y \in \mathbb{R}$, e.g. $\log y^{\prime} \sim \mathcal{N}(\rho \log y, \varepsilon)$, and default takes a threshold form, i.e.

$$
d\left(\beta, y, b_{S}, b_{L}\right)= \begin{cases}0, & \text { if } y \geq \bar{y}_{d}\left(\beta, b_{S}, b_{L}\right) \\ 1, & \text { otherwise }\end{cases}
$$

The default threshold $\bar{y}_{d}$ is implicitly determined by the indifference condition

$$
V^{p}\left(\beta, \bar{y}_{d}, b_{S}, b_{L}\right)=V^{d}\left(\beta, \bar{y}_{d}\right)
$$

The first-order condition with respect to the bond of maturity $i$ is

$$
-\left[q_{i}+\frac{\partial q_{S}}{\partial b_{i}^{\prime}} \ell_{S}+\frac{\partial q_{L}}{\partial b_{i}^{\prime}} \ell_{L}\right] u^{\prime}(c)=\beta \int_{\bar{y}_{d}\left(b_{S}^{\prime}, b_{L}^{\prime}\right)}^{\infty} \frac{\partial V^{\prime p}}{\partial b_{i}^{\prime}} d F\left(\beta^{\prime}, y^{\prime} \mid \beta, y\right) .
$$

The envelope condition for the stock of debt of maturity $i$ is

$$
\frac{\partial V^{p}\left(\beta, y, b_{S}, b_{L}\right)}{\partial b_{i}}=-\left[\kappa_{i}+\left(1-\delta_{i}\right) q_{i}\left(\beta, y, b_{S}^{\prime}, b_{L}^{\prime}\right)\right] u^{\prime}(c)
$$

Together, they reduce to the maturity-specific Euler equation:

$$
\left[\frac{\partial}{\partial b_{i}^{\prime}}\left(q_{S} \ell_{S}+q_{L} \ell_{L}\right)\right] u^{\prime}(c)=\beta \int_{\bar{y}_{d}\left(b_{S}^{\prime}, b_{L}^{\prime}\right)}^{\infty}\left[\kappa_{i}+\left(1-\delta_{i}\right) q_{i}\left(\beta^{\prime}, y^{\prime}, b_{S}^{\prime \prime}, b_{L}^{\prime \prime}\right)\right] u^{\prime}\left(c^{\prime}\right) d F\left(\beta^{\prime}, y^{\prime} \mid \beta, y\right)
$$

where $b_{i}^{\prime \prime}$ is the stock of maturity $i$ chosen next period, in state $\left\langle\beta^{\prime}, y^{\prime}, b_{S}^{\prime}, b_{L}^{\prime}\right\rangle$. The LHS reflects the consumption benefits this period provided by the increase in the bond sale proceeds due to additional issuance while the RHS captures the cost of increased debt service payments next period. The slopes of the bond price schedules with respect to the future debt level provide incentives for the sovereign, by adjusting the price for the weakly increasing default risk. The RHS cost is adjusted for the hedging benefit of maturity $i$, the comovement between $q_{i}$ and $u^{\prime}\left(c^{\prime}\right)$ across various possible realization of $\left\langle\beta^{\prime}, y^{\prime}\right\rangle$ next period ${ }^{7}$. For example, when fundamentals are weak due to a low endowment realization, consumption is low, marginal

\footnotetext{
${ }^{7}$ In the Arellano-Ramanarayanan case of $\delta_{S}=1$ the short bond has no hedging role. We also explore this case in the quantitative section below.
} 
utility is high, default probability is high, and bond prices are low. The bond price and marginal utility move in opposite directions so that their correlation is negative.

We can divide the two Euler question for the two maturity and highlight the relative incentive and hedging benefits of the two maturities:

$$
\frac{q_{S}+\frac{\partial q_{S}}{\partial b_{S}^{\prime}} \ell_{S}+\frac{\partial q_{L}}{\partial b_{S}^{\prime}} \ell_{L}}{q_{L}+\frac{\partial q_{S}}{\partial b_{L}^{\prime}} \ell_{S}+\frac{\partial q_{L}}{\partial b_{L}^{\prime}} \ell_{L}}=\frac{\mathbb{E}\left\{\left[\kappa_{S}+\left(1-\delta_{S}\right) q_{S}\left(\beta^{\prime}, y^{\prime}, b_{S}^{\prime \prime}, b_{L}^{\prime \prime}\right)\right] u^{\prime}\left(c^{\prime}\right) \mid y^{\prime}>\bar{y}_{d}\right\}}{\mathbb{E}\left\{\left[\kappa_{L}+\left(1-\delta_{L}\right) q_{L}\left(\beta^{\prime}, y^{\prime}, b_{S}^{\prime \prime}, b_{L}^{\prime \prime}\right)\right] u^{\prime}\left(c^{\prime}\right) \mid y^{\prime}>\bar{y}_{d}\right\}}
$$

The first-order condition for the Nash bargaining problem, for maturity $i$ is

$$
\begin{gathered}
\frac{\alpha}{\Delta_{\mathrm{Sov}}} \beta \mathbb{E} \frac{\partial V\left(\beta, y, \gamma_{S}, \gamma_{L}\right)}{\partial \gamma_{i}}+\frac{(1-\alpha)}{\Delta_{\text {Cre }}} \frac{\partial\left(q_{S} \gamma_{S}+q_{L} \gamma_{L}\right)}{\partial \gamma_{i}}=0 \\
\frac{(1-\alpha)}{\Delta_{\text {Cre }}} \frac{\partial\left(q_{S} \gamma_{S}+q_{L} \gamma_{L}\right)}{\partial \gamma_{i}}=\frac{\alpha}{\Delta_{\text {Sov }}} \beta \int_{\bar{y}_{d}\left(\gamma_{S}, \gamma_{L}\right)}^{\infty}\left[\kappa_{i}+\left(1-\delta_{i}\right) q_{i}\left(\beta^{\prime}, y^{\prime}, b_{S}^{\prime}, b_{L}^{\prime}\right)\right] u^{\prime}\left(c^{\prime}\right) d F\left(\beta^{\prime}, y^{\prime} \mid \beta, y\right) .
\end{gathered}
$$

where $b_{i}^{\prime}$ is the stock of maturity $i$ chosen next period, in state $\left\langle\beta^{\prime}, y^{\prime}, \gamma_{S}, \gamma_{L}\right\rangle$.

Dividing the expressions for both maturities,

$$
\frac{q_{S}+\frac{\partial q_{S}}{\partial \gamma_{S}} \gamma_{S}+\frac{\partial q_{L}}{\partial \gamma_{S}} \gamma_{L}}{q_{L}+\frac{\partial q_{S}}{\partial \gamma_{L}} \gamma_{S}+\frac{\partial q_{L}}{\partial \gamma_{L}} \gamma_{L}}=\frac{\mathbb{E}\left\{\left[\kappa_{S}+\left(1-\delta_{S}\right) q_{S}\left(\beta^{\prime}, y^{\prime}, b_{S}^{\prime}, b_{L}^{\prime}\right)\right] u^{\prime}\left(c^{\prime}\right) \mid y^{\prime}>\bar{y}_{d}\right\}}{\mathbb{E}\left\{\left[\kappa_{L}+\left(1-\delta_{L}\right) q_{L}\left(\beta^{\prime}, y^{\prime}, b_{S}^{\prime}, b_{L}^{\prime}\right)\right] u^{\prime}\left(c^{\prime}\right) \mid y^{\prime}>\bar{y}_{d}\right\}} .
$$

We find that the choice of maturity in ex-post negotiation largely follows the same incentivesvs-insurance trade-off faced by the sovereign when choosing its debt issuance during regular market access periods. Equations (26) and (28), governing maturity choice at issuance and during negotiation respectively, prescribe the same maturity composition for debt swap as for issuance whenever $\gamma_{i}=\ell_{i}$ and $b_{i}=0$, i.e. a "fresh start" with no outstanding debt at the start of the period.

On the other hand, two differences are noteworthy. First, whenever $b_{i} \neq 0$, even if $\gamma_{i}=\ell_{i}$, the LHS of the two relative conditions will no longer coincide. This is because while in swap negotiations we start anew, during normal market access we issue relative to a baseline of outstanding debt, a form of "debt overhang." Second, the determination of the absolute level of indebtedness is different between the two scenarios, whenever

$$
u^{\prime}(c) \neq \frac{1-\alpha}{\alpha} \frac{\Delta_{\text {Sov }}}{\Delta_{\text {Cre }}}
$$

The Nash solution and the sovereign's issuance policies will not coincide in the level of debt but rather only in the maturity mix. 


\section{Quantitative Analysis}

\subsection{Calibration}

We target salient Greek data moments, with the aim of evaluating the model against the 2012 default and swap $^{8}$, involving private creditors alone. This choice is motivated by the magnitude of the swap and the availability of relatively high-quality, recent data. We calibrate the model to a yearly frequency. We set $\delta_{S}=1$ and $\delta_{L}=0.064$ so that they have risk-free Macaulay durations of 1 and 10 years respectively. The short-bond is thus one-period debt, as in Arellano and Ramanarayanan [2012]. The risk-free rate is set to $4 \%$, the widely used, conventional value in the literature. The probability of renegotiating and returning to market, $\eta$, is set so that it induces a six year average duration of exclusion from markets, in line with the evidence of Beim and Calomiris [2001] $]^{9}$. The endowment process is assumed AR(1), its parameters (autocorrelation $\rho$ and innovation standard deviation $\sigma_{\varepsilon}$ ) are estimated using OECD National Accounts data and the process is discretized using the Rouwenhorst method of Kopecky and Suen [2010].

$$
\log y_{t}=\rho \log y_{t-1}+\sigma_{\varepsilon} \varepsilon, \quad \varepsilon \sim \text { i.i.d. } \mathcal{N}(0,1)
$$

All annual data is Hodrick-Prescott filtered with parameter value of 100 . The data counterpart for the endowment process is GDP minus Gross Capital Formation, given that we abstract from investment and production.

The felicity function is assumed to have a constant coefficient of relative risk aversion $\sigma$,

$$
u(c)=\frac{c^{1-\sigma}-1}{1-\sigma}
$$

and we set $\sigma=2$ in line with the literature, while the default output cost follows Chatterjee and Eyigungor [2012],

$$
h(y)=y-\max \left\{0, \lambda_{0} y+\lambda_{1} y^{2}\right\} .
$$

with $\lambda_{0}<0, \lambda_{1}>0$ and no output cost for endowments draws lower than $-\lambda_{0} / \lambda_{1}$. For the benchmark economy we allow for 2 regimes, with discount factors $\beta_{L}$ and $\beta_{H}$, following a Markov chain with transition matrix $\Pi_{\beta}$, and we assume the two regimes are symmetric.

$$
\Pi_{\beta}=\left[\begin{array}{ll}
\beta_{L L} & \beta_{L H} \\
\beta_{H L} & \beta_{H H}
\end{array}\right]=\left[\begin{array}{cc}
\psi & 1-\psi \\
1-\psi & \psi
\end{array}\right]
$$

In the endowment-shock-only calibration $\beta$ is constant. The remaining parameters, related to discounting $(\beta, \psi)$, the output cost of default $\left(\lambda_{0}, \lambda_{1}\right)$, and bargaining parameters $\left(\alpha, \mu_{S}\right)$

\footnotetext{
${ }^{8}$ In so doing we must unavoidably abstract from several institutional details, possibly of note. In particular, we abstract for any role from official lending, conditionality, and more generally the involvement of International Financial Intermediaries and the Troika. Boz [2011] and Dellas and Niepelt [2016] study official lending in settings with one-period debt only.

${ }^{9}$ Arellano and Ramanarayanan [2012] calibrate the reentry probability based on the results of Benjamin and Wright [2009] who find a slightly lower mean exclusion duration of 5 years. Estimates of this parameter are sensitive to sample selection. In general, more recent episodes are resolved faster, with a larger haircut suffered by creditors. This trend is in part driven by the difference between the syndicated bank lending regime of the '80s and the subsequent market-based Brady bonds era. Bai and Zhang [2012] provide an analysis of these market structure changes.
} 
are picked to match key moments: the share of short debt in the portfolio, the volatility of consumption relative to GDP, the cyclical behavior of net exports, the average haircut, and the difference between the haircuts applied to short- and long-term bonds. Table 1 includes the calibrated parameter values while Table 2 reports the model's fit over the targeted moments.

With a wider gap between $\beta_{L}$ and $\beta_{H}$, we can induce a greater extension of maturity during the swap, at the cost of increased business cycle volatility. The relative volatility of consumption to GDP is used to discipline the stochastic properties of the discount factor (difference between types and turnover probability/mean tenure length).

The mean level of external debt and the maturity structure at issuance are most sensitive to the mean level of the discount factor together with the parameters of the penalty function $h$. The remaining parameters are closely connected to the mean haircut level as we as the degree of haircut heterogeneity.

\begin{tabular}{crrl}
\hline \multicolumn{2}{c}{$\begin{array}{r}\text { Benchmark } \\
\text { Model }\end{array}$} & $\begin{array}{c}\text { Endowment } \\
\text { Shock Only }\end{array}$ & \\
Common Parameters & & \\
\hline$\sigma$ & 2.0 & & Coef. of relative risk-aversion \\
$r$ & 0.04 & & Risk-free rate \\
$\delta_{S}$ & 1.0 & 1 year duration \\
$\delta_{L}$ & 0.064 & & 10 years duration \\
$\eta$ & 0.2 & & Bargaining probability \\
$\rho$ & 0.9 & & Endow. autocorrelation \\
$\varepsilon$ & 0.021 & & Endow. shock st. deviation \\
& & & \\
Targeted Moments & & \\
\hline$\beta$ & $0.86 \pm 0.04$ & 0.87 & Discounting \\
$\lambda_{0}$ & -0.42 & -0.43 & Output loss \\
$\lambda_{1}$ & 0.485 & 0.49 & Output loss \\
$\alpha$ & 0.81 & 0.81 & Sov's bargaining power \\
$\mu_{S}$ & 0.5 & 0.5 & Ex-post assignment \\
$\psi$ & 0.825 & 1.0 & Turnover risk, Pr $\left(\beta^{\prime}=\beta\right)$ \\
\hline
\end{tabular}

Table 1: Calibration. See section 4.1 for details and Table 2 for moments fit.

\subsection{Quantitative Results}

Table 2 reports key business cycle and debt moments in the data and in both of the two model specifications. Concerning business cycle moments, the model can generate a volatility of consumption greater than that of GDP of 1.1-1.3, close to the data value of 1.2, and an essentially acyclical NX-to-GDP ratio, whereas in our sample the ratio is mildly countercyclical. Either calibrations can induce the sovereign to hold a share of short-term debt of one third, same as in the data. Note that in the model, there's a one-to-one relation between the share 
of short and duration, given equation (3).

For the debt-to-GDP ratio, we restrict attention to external bonds and notes only, and we find an average value of 0.5 in our 2004-2015 sample. The time plot of this variable raises stationarity concerns: indebtedness increases prior to the crisis and plummets to 0.2. See Figure 3. In the model, debt averages around 0.3 under either specifications.

Stationarity concerns are also apparently in relation to the spreads data. We compute spreads relative to German bonds of equivalent maturity. The time series plot of Figure 3 hints at a structural break around the time of admittance into the Euro area: convergence to Euro area spreads, the Euro membership period starting in 2001, and the eventual spike in spreads during the crisis, starting in early 2010. For the purposes of Table 2 we report spread statistics over the period $2000-2010$ only.

\section{$\begin{array}{rrr} & \text { Benchmark } & \text { Endowment } \\ \text { Data } & \text { Model } & \text { Shock Only }\end{array}$}

\begin{tabular}{lrrr} 
Targeted Moments & & & \\
\hline Std C / Std GDP & 1.2 & 1.3 & 1.1 \\
Corr NX/GDP, GDP & -0.14 & 0.04 & 0.14 \\
Share of Short in Total Debt & 0.33 & 0.30 & 0.35 \\
Total Debt to GDP & $0.5^{\ddagger}$ & 0.37 & 0.36 \\
Aggregate Haircut & 0.7 & 0.7 & 0.7 \\
1-year Haircut & 0.8 & 0.81 & 0.85 \\
& & & \\
Spreads & & & $3 \%$ \\
\hline 1-year Spread & $1 \%^{\dagger}$ & $2 \%$ & $2 \%$ \\
10-year Spread & $1 \%{ }^{\dagger}$ & $2 \%$ & $4 \%$ \\
Std 1-year Spread & $1 \%$ & $3 \%$ & $1 \%$ \\
Std 10-year Spread & $1 \%$ & $1 \%$ & \\
\hline
\end{tabular}

Table 2: Business cycle and debt moment, data versus model ergodic distribution.

$\dagger$ Spreads moments over 2000-2010 only. † External debt to GDP available for 2004-2015. See Figure 3 and comments in main text.

The model can generate the target level of the aggregate haircut at $70 \%$, as well as the broad pattern of haircut heterogeneity reported by Zettelmeyer et al. [2013] and further emphasized by Asonuma et al. [2017]. See Table 4 for haircut statistics and Figure 7 for the relation between haircuts and endowment realization at the time of negotiations.

Table 3 highlights the main difference between the two model environments: when driven by endowments shocks alone, the model is unable to replicate the maturity extension documented in the data, maturity collapses from about 8 years to a little over 1 year, while under the full specification, with both an endowment and political turnover shocks, the model generates the average increase in maturity upon return to market, maturity lengthens from 6.5 years to 7.3. To understand the failure of the basic setup and the role of the political economy friction in the full model, we start by plotting the choice of maturity, at issuance and during the swap, in 


\begin{tabular}{|c|c|c|c|c|c|c|}
\hline & \multicolumn{2}{|c|}{ Greece 2012} & \multicolumn{2}{|c|}{$\begin{array}{c}\text { Benchmark } \\
\text { Model }\end{array}$} & \multicolumn{2}{|c|}{$\begin{array}{l}\text { Endowment } \\
\text { Shock Only }\end{array}$} \\
\hline & Before & After & Before & After & Before & After \\
\hline Duration & 6.4 & 7.8 & 6.5 & 7.3 & 8.0 & 1.3 \\
\hline Debt to GDP & 0.7 & 0.2 & 0.6 & 0.1 & 0.4 & 0.1 \\
\hline
\end{tabular}

Table 3: Maturity extension. Debt duration and levels, relative to GDP, at the time of default and following the swap. Data is from Zettelmeyer et al. [2013] and the OECD.

\begin{tabular}{lcrrrr}
\hline & Greece & \multicolumn{2}{c}{ Benchmark Model } & \multicolumn{2}{c}{ Endowment Shock } \\
Haircut & $\mathbf{2 0 1 2}$ & Market & Face Value & Market & Face Value \\
\hline Aggregate & 0.70 & 0.70 & 0.70 & 0.68 & 0.71 \\
Short (1-y) & 0.80 & 0.82 & 0.81 & 0.85 & 0.85 \\
Long (10-y) & 0.40 & 0.62 & 0.63 & 0.59 & 0.63 \\
\hline
\end{tabular}

Table 4: Haircuts applied to 1-year and 10-year bonds in the data reported by Zettelmeyer et al. [2013] versus model-generated average haircuts. "Market" haircuts use the exit spreads implied in $q_{i}\left(\beta, y, \gamma_{S}, \gamma_{L}\right)$ to value the exit portfolio $\left(\gamma_{S}, \gamma_{L}\right)$ while "Face Value" uses risk-free bond prices.

Figures 4 and 6 . Note that in the endowment-shock-only environment, while the government is willing to lengthen maturity during normal issuance, the Nash solution always picks a very short maturity during the swap, especially for negotiations taking place with below-average endowment draws. This disconnect can be understood in light of our findings in Section 3.6. During times of normal market access the sovereign is rolling over debt in excess of one quarter's worth of GDP, during the swap debt is greatly reduces and the choice of maturity is identical to that of an issuer inheriting no debt from the previous period. This is the "fresh start" equivalence result from equations (25) and (28). In Figure 5 we plot the time path of short- and long-term debt, in the endowment-shock-only model, when we start the country with no outstanding debt in period 1 , and feed a sequence of mean endowment realizations. We find that it takes the sovereign 4 years before it issues any long-term debt. This is because, at low debt levels, the gain from more favorable prices for short-term debt outweighs the benefits of hedging induced by future long-term bond price changes. When the country finds itself without debt and start accumulating it, there's little scope for insurance.

The dominance of the incentive benefits of short debt is contingent upon dealing with a rather present-oriented borrower. Throughout, we maintain the usual assumption that $\beta(1+r)<1$, but we allow $\beta$ to vary in the benchmark specification. With two policy stances, or government types, we see in Figure 6 , that the more patient type will issue more long-term debt and enjoy relatively more insurance, given that its temptation to default is lower than the impatient type's, all other things constant.

Finally, our results throughout are consistent with the evidence on haircut heterogeneity previously discussed. We find that lenders can recover relatively more whenever the endowment 


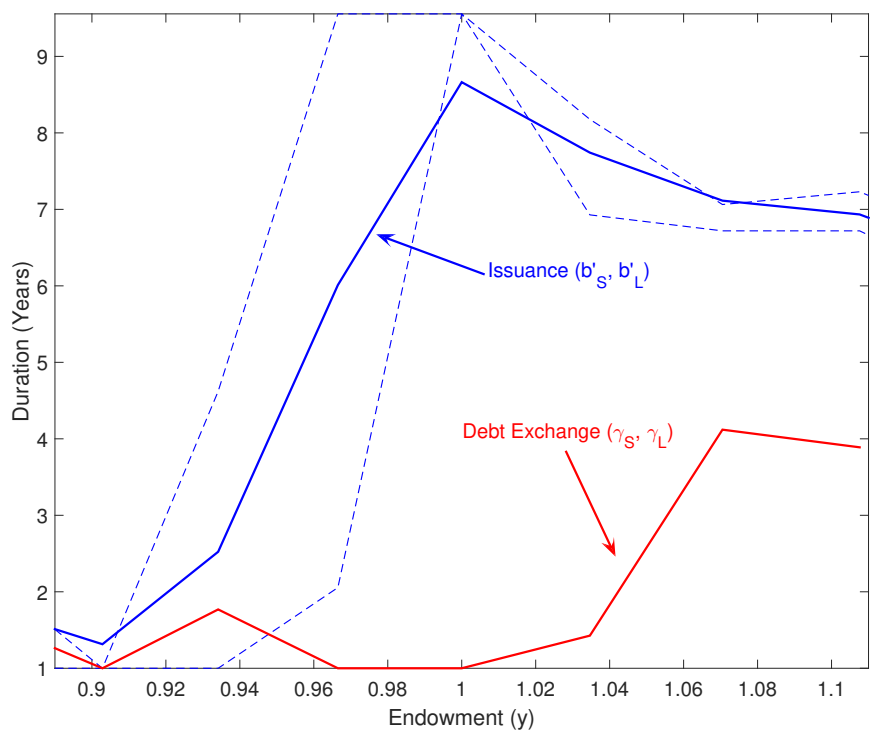

Figure 4: Endowment shock only. Average chosen duration, by endowment realization, at issuance (blue) and as part of the swap (red). The exit portfolio $\left(\gamma_{S}, \gamma_{L}\right)$ depends on the endowment realization alone. At issuance we average over start-of-period debt levels $\left(b_{S}, b_{L}\right)$. Dashed lines represent 25 and 75 percentiles.

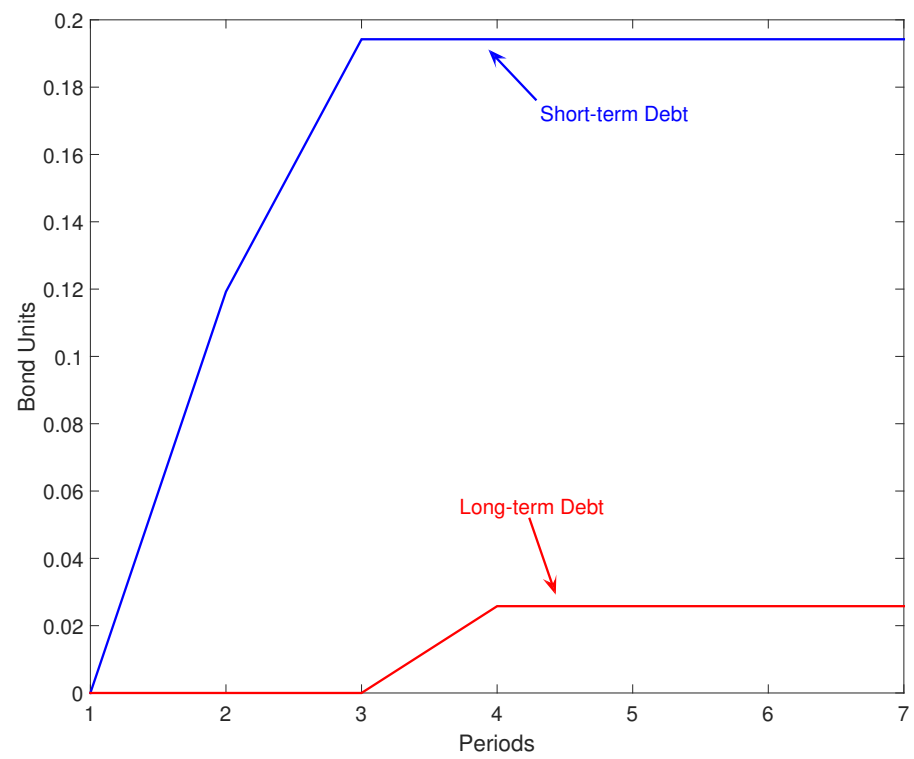

Figure 5: Endowment shock only. Time path of outstanding debt, by maturity, starting without debt. Endowment is kept constant at its mean value. 


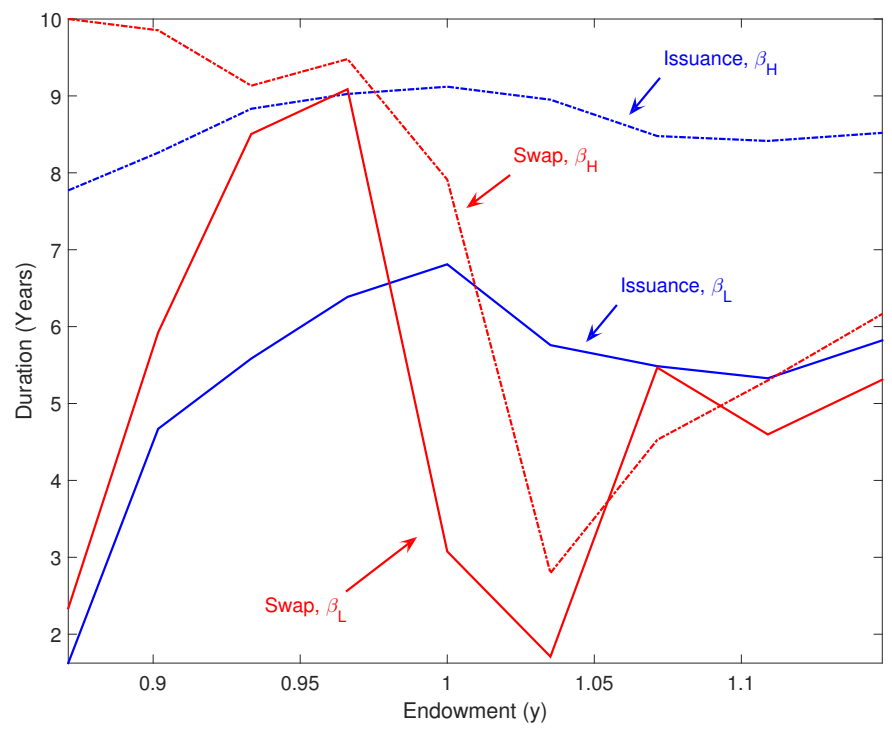

Figure 6: Benchmark model, with endowment and demand shocks. Average duration of next period's debt, by endowment realization, at issuance (blue) and following the swap (red). Low discount factor policies in solid lines, high discount factor dashed.

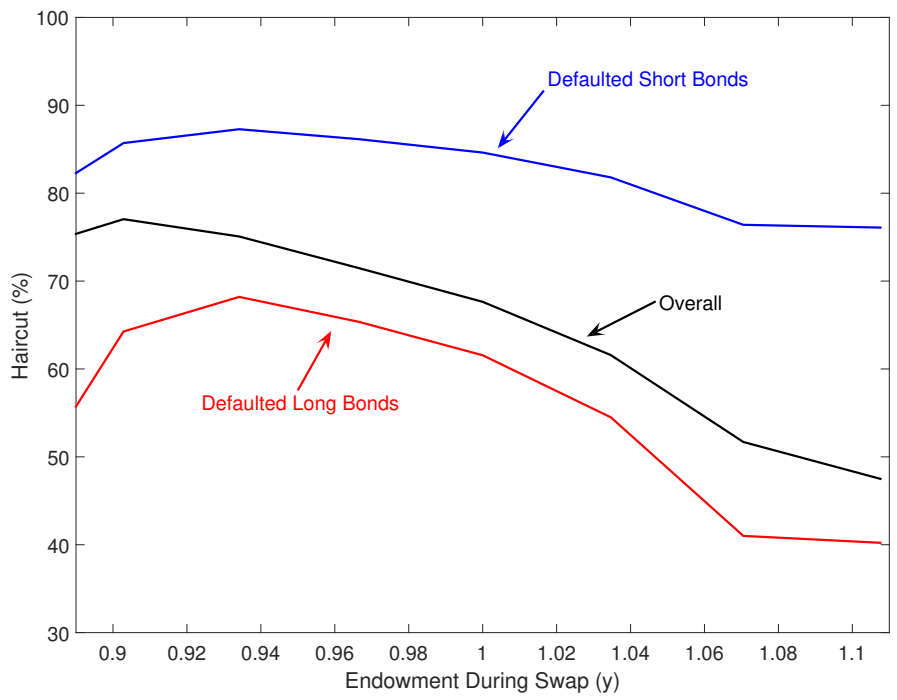

Figure 7: Haircuts, by outstanding maturity, versus endowment realization. Haircuts are lower for swaps taking place during downturns and for longer-maturity debt. 
draw is higher or the sovereign is more patient. Systematically, lenders holding the defaulted short-term bonds recover less, with exactly how much less being determined by the share of short-term debt in the portfolio at the time of default.

\section{Conclusion}

We started by reviewing the evidence on sovereign debt swaps and found that maturity extension is a key feature of swaps in the data. We showed that with endowments shock alone, a model of maturity choice and renegotiation cannot deliver this behavior. We provided an explanation for this failure in terms of the well understood trade-off between repayment incentives and hedging/insurance, by establishing an equivalence between the choice of maturity at issuance, in particular states of the world, and during the swap.

Finally, we resolved this disconnect between data and standard theory by introducing political turnover risk, in a reduced-form, motivated by the political economy of sovereign borrowing, including the older idea of "populist policy cycles." Governments alternates between more or less patient stances, spells of "austerity" and "fiscal profligacy." We interpret our finding as lending further credibility to the idea that political economy frictions and other demand features need to play a role in our accounts of sovereign crises, beyond the usual structure driven by endowment (or productivity) shocks, under lack of commitment. 


\section{References}

Mark Aguiar and Manuel Amador. Growth in the Shadow of Expropriation. The Quarterly Journal of Economics, 126(2):651-697, 2011.

Mark Aguiar and Manuel Amador. Take the short route: How to repay and restructure sovereign debt with multiple maturities, 2014.

Mark Aguiar and Gita Gopinath. Defaultable debt, interest rates and the current account. Journal of international Economics, 69(1):64-83, 2006.

Cristina Arellano. Default Risk and Income Fluctuations in Emerging Economies. American Economic Review, 98(3):690-712, June 2008.

Cristina Arellano and Yan Bai. Fiscal Austerity During Debt Crises. June 2014

Cristina Arellano and Ananth Ramanarayanan. Default and the Maturity Structure in Sovereign Bonds. Journal of Political Economy, 120(2):187 - 232, 2012.

Tamon Asonuma. Serial default and debt renegotiation. MPRA Paper 55139, University Library of Munich, Germany, April 2012.

Tamon Asonuma, Dirk Niepelt, and Romain Ranciere. Sovereign bond prices, haircuts and maturity. IMF Working Papers 17/119, International Monetary Fund, 2017.

Tamona Asonuma, Dirk Niepelt, and Romain Ranciere. Sovereign Debt Restructuring and the Short-term Debt Curse. June 2015.

Yan Bai and Jing Zhang. Duration of sovereign debt renegotiation. Journal of International Economics, 86(2):252-268, 2012.

Yan Bai, Seon Tae Kim, and Gabriel Mihalache. The Maturity and Payment Schedule of Sovereign Debt. Working Paper 20896, National Bureau of Economic Research, January 2015.

D.O. Beim and C.W. Calomiris. Emerging Financial Markets. Finance, Insurance, and Real Estate Series. McGraw-Hill/Irwin, 2001. ISBN 9780072425147.

David Benjamin and Mark L. J. Wright. Recovery Before Redemption: A Theory Of Delays In Sovereign Debt Renegotiations. CAMA Working Papers 2009-15, Centre for Applied Macroeconomic Analysis, Crawford School of Public Policy, The Australian National University, April 2009.

Javier Bianchi, Juan Carlos Hatchondo, and Leonardo Martinez. International Reserves and Rollover Risk. NBER Working Papers 18628, National Bureau of Economic Research, Inc, December 2012.

Bloomberg. Professional Service, Terminal, June 2015. 
Emine Boz. Sovereign default, private sector creditors, and the ifis. Journal of International Economics, 83(1):70 - 82, 2011. ISSN 0022-1996. doi: http://dx.doi.org/10.1016/j. jinteco.2010.10.001.

Fernando A. Broner, Guido Lorenzoni, and Sergio L. Schmukler. Why Do Emerging Economies Borrow Short Term? Journal of the European Economic Association, 11:67-100, 012013.

Jeremy Bulow and Kenneth Rogoff. Sovereign Debt: Is to Forgive to Forget? American Economic Review, 79:43-50, 1989.

Satyajit Chatterjee and Burcu Eyigungor. Maturity, Indebtedness, and Default Risk. American Economic Review, 102(6):2674-99, October 2012.

Juan J. Cruces and Christoph Trebesch. Sovereign Defaults: The Price of Haircuts. American Economic Journal: Macroeconomics, 5(3):85-117, July 2013.

Gabriel Cuadra and Horacio Sapriza. Sovereign default, interest rates and political uncertainty in emerging markets. Journal of International Economics, 76(1):78-88, September 2008.

Harris Dellas and Dirk Niepelt. Sovereign debt with heterogeneous creditors. Journal of International Economics, 99:S16 - S26, 2016. ISSN 0022-1996. doi: http://dx.doi.org/10. 1016/j.jinteco.2015.12.002. 38th Annual NBER International Seminar on Macroeconomics.

Rudiger Dornbusch and Sebastian Edwards. The Macroeconomics of Populism in Latin America, 1991.

Jonathan Eaton and Mark Gersovitz. Debt with potential repudiation: Theoretical and empirical analysis. The Review of Economic Studies, 48(2):289-309, 1981.

Global Financial Data. GF Database, October 2015.

Juan Carlos Hatchondo and Leonardo Martinez. Long-duration bonds and sovereign defaults. Journal of International Economics, 79(1):117-125, 2009.

Juan Carlos Hatchondo, Leonardo Martinez, and Horacio Sapriza. Heterogeneous Borrowers In Quantitative Models Of Sovereign Default. International Economic Review, 50(4):11291151, November 2009.

Juan Carlos Hatchondo, Leonardo Martinez, and Horacio Sapriza. Quantitative properties of sovereign default models: solution methods. Review of Economic Dynamics, 13(4): 919-933, October 2010.

Juan Carlos Hatchondo, Leonardo Martinez, and CÃl'sar Sosa Padilla. Voluntary sovereign debt exchanges. Journal of Monetary Economics, 61(C):32-50, 2014.

Juan Carlos Hatchondo, Leonardo Martinez, and Francisco Roch. Fiscal rules and the Sovereign Default Premium. Caepr Working Papers 2015-010 Classification-F, Center for Applied Economics and Policy Research, Economics Department, Indiana University Bloomington, March 2015. 
Ehud Kalai and Meir Smorodinsky. Other solutions to Nash's bargaining problem. Econometrica: Journal of the Econometric Society, pages 513-518, 1975.

Karen A Kopecky and Richard MH Suen. Finite state Markov-chain approximations to highly persistent processes. Review of Economic Dynamics, 13(3):701-714, 2010.

Philip Lane. The European Sovereign Debt Crisis. Journal of Economic Perspectives, 26(3): 49-68, 2012.

Sandra Valentina Lizarazo. Default risk and risk averse international investors. Journal of International Economics, 89(2):317 - 330, 2013. ISSN 0022-1996. doi: http://dx.doi.org/ 10.1016/j.jinteco.2012.08.006.

Frederick R. Macaulay. Some Theoretical Problems Suggested by the Movements of Interest Rates, Bond Yields and Stock Prices in the United States since 1856. National Bureau of Economic Research, Inc, 1938.

Enrique G. Mendoza and Vivian Z. Yue. A General Equilibrium Model of Sovereign Default and Business Cycles. The Quarterly Journal of Economics, 127(2):889-946, 2012.

Rohan Pitchford and Mark L. J. Wright. Holdouts in Sovereign Debt Restructuring: A Theory of Negotiation in a Weak Contractual Environment. Review of Economic Studies, 79(2): 812-837, 2012.

Carmen M. Reinhart and Christoph Trebesch. The pitfalls of external dependence: Greece, 1829-2015. Working Paper 21664, National Bureau of Economic Research, October 2015.

Jeffrey D. Sachs. Social Conflict and Populist Policies in Latin America. Working Paper 2897, National Bureau of Economic Research, March 1989.

Juan M Sánchez, Horacio Sapriza, and Emircan Yurdagul. Sovereign Default and the Choice of Maturity. Federal Reserve Bank of St. Louis Working Paper Series, (2014-031), April 2015.

Almuth Scholl. The Dynamics of Sovereign Default Risk and Political Turnover. Working Paper Series of the Department of Economics, University of Konstanz 2015-05, Department of Economics, University of Konstanz, February 2015.

Federico Sturzenegger and Jeromin Zettelmeyer. Debt defaults and lessons from a decade of crises. MIT press, 2006.

Federico Sturzenegger and Jeromin Zettelmeyer. Creditors' Losses Versus Debt Relief: Results from a Decade of Sovereign Debt Crises. Journal of the European Economic Association, 5(2-3):343-351, 04-05 2007.

Michael Tomz and Mark L.J. Wright. Empirical Research on Sovereign Debt and Default. Annual Review of Economics, 5(1):247-272, 052013.

Christoph Trebesch, Michael G Papaioannou, and Udaibir S. Das. Sovereign Debt Restructurings 1950-2010: Literature Survey, Data, and Stylized Facts. IMF Working Papers 12/203, International Monetary Fund, August 2012. 
Vivian Z. Yue. Sovereign default and debt renegotiation. Journal of International Economics, 80(2):176-187, March 2010.

Jeromin Zettelmeyer, Christoph Trebesch, and Mitu Gulati. The Greek debt restructuring: an autopsy. Economic Policy, 28(75):513-563, 2013.

\section{A Numerical Solution}

We set $\# \mathbb{Y}=9, \# \mathbb{B}=2$, and use 150 grid points for each maturity ( $b_{S}$ and $b_{L}$ ), equally spaced over $[0,0.5]$, where 1 is the mean endowment level. We solve on the grid, by considering the limit of the finite horizon economy. Se initialize all values and policies to zero, and iterate backwards for at least 5000 iterations (years). We then check key moments of the ergodic distribution, e.g. Tables 2-4 and averaged policies in Figure 6, for convergence.

Step 1: Initialize $V, V^{d}, V^{p}, \ell_{i}$, and $\gamma_{i}$ to 0.0 everywhere (initializing the policies is needed for the evaluation of the tails of cash flows in the equation for bond prices). Compute the value of permanent autarky, $V^{\text {aut }}$, by iterating on equation (9).

Step 2: Iterate:

1. Iterate on equations (7) and (17) to update value functions and borrowing policies $\ell_{i}$;

2. Take the maximum over the two options to update the default policy in equation (5);

3. Solve the Nash problem (12), by grid search, to update the renegotiation policies $\gamma_{i}$;

4. Iterate on equation (18) for $q_{S}$ and $q_{L}$ to update bond prices, and on equation (19) for the recovery values $\chi_{S}$ and $\chi_{L}$.

Step 3: Check for convergence and simulate.

\section{B Trilateral Nash Bargaining}

In Section 3.6 we characterized the choice of maturity during debt swap under the assumption that all lenders are represented by a single committee. Then, the Nash bargaining power of the lenders $1-\alpha$ and the ex-post assignment parameter $\mu_{S}$ control the outcome of bargaining. In this appendix we explore an alternative assumption: short and long bond holders are separate parties in the bargaining process, with bargaining powers $(1-\alpha) \alpha_{S}$ and $(1-\alpha)\left(1-\alpha_{S}\right)$. We now show that a judicious choice of the $\alpha_{S}$ parameter can induce the same outcomes as a given $\mu_{S}$ parameter under the baseline assumption.

The old short bond holders will receive $\left\langle\gamma_{S}^{S}, \gamma_{L}^{S}\right\rangle$ following the swap, the old long creditors will receive $\left\langle\gamma_{S}^{L}, \gamma_{L}^{L}\right\rangle$ and let $\gamma_{S}=\gamma_{S}^{S}+\gamma_{S}^{L}$ and $\gamma_{L}=\gamma_{L}^{S}+\gamma_{L}^{L}$. Then, the surplus of the old short bond holders is

$$
\Delta_{\text {Cre }}^{S}=q_{S}\left(\beta, y, \gamma_{S}, \gamma_{L}\right) \gamma_{S}^{S}+q_{L}\left(\beta, y, \gamma_{S}, \gamma_{L}\right) \gamma_{L}^{S}
$$


and that of the old long bond holders is

$$
\Delta_{\mathrm{Cre}}^{L}=q_{S}\left(\beta, y, \gamma_{S}, \gamma_{L}\right) \gamma_{S}^{L}+q_{L}\left(\beta, y, \gamma_{S}, \gamma_{L}\right) \gamma_{L}^{L}
$$

The Nash problem becomes

$$
\begin{gathered}
\underset{\gamma_{S}^{S}, \gamma_{S}^{L}, \gamma_{L}^{S} \cdot \gamma_{L}^{L}}{\operatorname{argmax}}\left[\Delta_{\text {Sov }}\right]^{\alpha}\left[\Delta_{\text {Cre }}^{S}\right]^{(1-\alpha) \alpha_{S}}\left[\Delta_{\text {Cre }}^{L}\right]^{(1-\alpha)\left(1-\alpha_{S}\right)} \\
\text { s.t. } \Delta_{\text {Sov }} \geq 0, \Delta_{\text {Cre }}^{S} \geq 0, \text { and } \Delta_{\text {Cre }}^{L} \geq 0 .
\end{gathered}
$$

Note that the sovereign's surplus is unaltered, since the country's payoff is a function of the total $\left\langle\gamma_{S}, \gamma_{L}\right\rangle$ units, and that each creditor group's recovery impacts the other's payoff through the default probability going forward, as reflected in the market value of the new units. This formulation has an inherent indeterminacy due to the fact that both lender groups are risk-neutral and use the same risk-free rate $r$. To see this, assume we found a solution $\left\langle\gamma_{S}^{S}, \gamma_{S}^{L}, \gamma_{L}^{S} \cdot \gamma_{L}^{L}\right\rangle$ to (33). Then, we can construct other solutions by reassigning $\varepsilon$ units of short to the old short lenders and compensating the old long lenders with $\left(q_{L} / q_{S}\right) \varepsilon$ units of the new long bonds, i.e. $\left\langle\gamma_{S}^{S}+\varepsilon, \gamma_{S}^{L}-q_{L} \varepsilon / q_{S}, \gamma_{L}^{S}-\varepsilon \cdot \gamma_{L}^{L}+q_{L} \varepsilon / q_{S}\right\rangle$ is also a solution. Note that the bond prices $q_{S}$ and $q_{L}$ do not change, as they are a function of the total new units only, not of the split among lenders.

We now show that among this continuum of solutions, the outcome characterized in the previous section is consistent with $\alpha_{S}=\mathcal{S}_{S}$. Again assuming a threshold default policy we can take the first order condition with respect to maturity $S$ for creditor group $S$ and $L$ respectively

$$
\begin{aligned}
& \frac{\alpha}{\Delta_{\text {Sov }}} \beta \mathbb{E} \frac{\partial V}{\partial \gamma_{S}}+\frac{(1-\alpha) \alpha_{S}}{\Delta_{\text {Cre }}^{S}} \frac{\partial\left(q_{S} \gamma_{S}^{S}+q_{L} \gamma_{L}^{S}\right)}{\partial \gamma_{S}^{S}}+\frac{(1-\alpha)\left(1-\alpha_{S}\right)}{\Delta_{\text {Cre }}^{L}} \frac{\partial\left(q_{S} \gamma_{S}^{L}+q_{L} \gamma_{L}^{L}\right)}{\partial \gamma_{S}^{S}}=0 \\
& \frac{\alpha}{\Delta_{\text {Sov }}} \beta \mathbb{E} \frac{\partial V}{\partial \gamma_{S}}+\frac{(1-\alpha) \alpha_{S}}{\Delta_{\text {Cre }}^{S}} \frac{\partial\left(q_{S} \gamma_{S}^{S}+q_{L} \gamma_{L}^{S}\right)}{\partial \gamma_{S}^{L}}+\frac{(1-\alpha)\left(1-\alpha_{S}\right)}{\Delta_{\text {Cre }}^{L}} \frac{\partial\left(q_{S} \gamma_{S}^{L}+q_{L} \gamma_{L}^{L}\right)}{\partial \gamma_{S}^{L}}=0
\end{aligned}
$$

The first term in (34-35) is independent of the creditor group so the two right-most terms must be equal.

$$
\begin{gathered}
\frac{\alpha_{S}}{\Delta_{\text {Cre }}^{S}} \frac{\partial\left(q_{S} \gamma_{S}^{S}+q_{L} \gamma_{L}^{S}\right)}{\partial \gamma_{S}^{S}}+\frac{\left(1-\alpha_{S}\right)}{\Delta_{\text {Cre }}^{L}} \frac{\partial\left(q_{S} \gamma_{S}^{L}+q_{L} \gamma_{L}^{L}\right)}{\partial \gamma_{S}^{S}}= \\
\frac{\alpha_{S}}{\Delta_{\text {Cre }}^{S}} \frac{\partial\left(q_{S} \gamma_{S}^{S}+q_{L} \gamma_{L}^{S}\right)}{\partial \gamma_{S}^{L}}+\frac{\left(1-\alpha_{S}\right)}{\Delta_{\text {Cre }}^{L}} \frac{\partial\left(q_{S} \gamma_{S}^{L}+q_{L} \gamma_{L}^{L}\right)}{\partial \gamma_{S}^{L}} \\
\frac{\alpha_{S}}{\Delta_{\text {Cre }}^{S}}\left(q_{S}+\frac{\partial q_{S}}{\partial \gamma_{S}} \gamma_{S}^{S}+\frac{\partial q_{L}}{\partial \gamma_{S}} \gamma_{L}^{S}\right)+\frac{\left(1-\alpha_{S}\right)}{\Delta_{\text {Cre }}^{L}}\left(\frac{\partial q_{S}}{\partial \gamma_{S}} \gamma_{S}^{L}+\frac{\partial q_{L}}{\partial \gamma_{S}} \gamma_{L}^{L}\right)= \\
\frac{\alpha_{S}}{\Delta_{\text {Cre }}^{S}}\left(\frac{\partial q_{S}}{\partial \gamma_{S}} \gamma_{S}^{S}+\frac{\partial q_{L}}{\partial \gamma_{S}} \gamma_{L}^{S}\right)+\frac{\left(1-\alpha_{S}\right)}{\Delta_{\text {Cre }}^{L}}\left(q_{S}+\frac{\partial q_{S}}{\partial \gamma_{S}} \gamma_{S}^{L}+\frac{\partial q_{L}}{\partial \gamma_{S}} \gamma_{L}^{L}\right) \\
\frac{\alpha_{S}}{\Delta_{\text {Cre }}^{S}}=\frac{\left(1-\alpha_{S}\right)}{\Delta_{\text {Cre }}^{L}}
\end{gathered}
$$


As previously argued, a continuum of splits of a given $\left\langle\gamma_{S}, \gamma_{L}\right\rangle$ restructuring package are solutions to the above problem. To check whether the outcome achieved under the assumptions made in the previous section is a solution here, note that

$$
\frac{\Delta_{\text {Cre }}^{S}}{\mathcal{S}_{S}}=\Delta_{\text {Cre }}=\frac{\Delta_{\text {Cre }}^{L}}{1-\mathcal{S}_{S}}
$$

and

$$
\frac{\gamma_{i}^{S}}{\mathcal{S}_{S}}=\gamma_{i}=\frac{\gamma_{i}^{L}}{1-\mathcal{S}_{S}}
$$

Equation (38) becomes

$$
\frac{\alpha_{S}}{\mathcal{S}_{S} \Delta_{\mathrm{Cre}}}=\frac{\left(1-\alpha_{S}\right)}{\left(1-\mathcal{S}_{S}\right) \Delta_{\mathrm{Cre}}}
$$

and it reduces to the condition $\alpha_{S}=\mathcal{S}_{S}$.

In summary, we found that the same outcome can be supported by either assuming that all lenders form a single committee with bargaining power $1-\alpha$, then split the new bonds according to parameter $\mu_{S}$ or by letting the old short and long bond holders have their own committees, with bargaining powers summing to $1-\alpha$ and fix the short bond holders' power parameter to the appropriate value.

This result hinges critically on the assumption of homogeneous lenders, characterized by the same, linear preferences and the same outside option $r$. A natural extension would be to consider environments in which short and long lenders are different in e.g. their attitude towards risk and thus self-select into one of the two maturities. In such a setting, to be studied in future work, we might be able to provide a deeper rationale for the observed heterogeneous haircuts.

\section{Additional Figures and Tables}




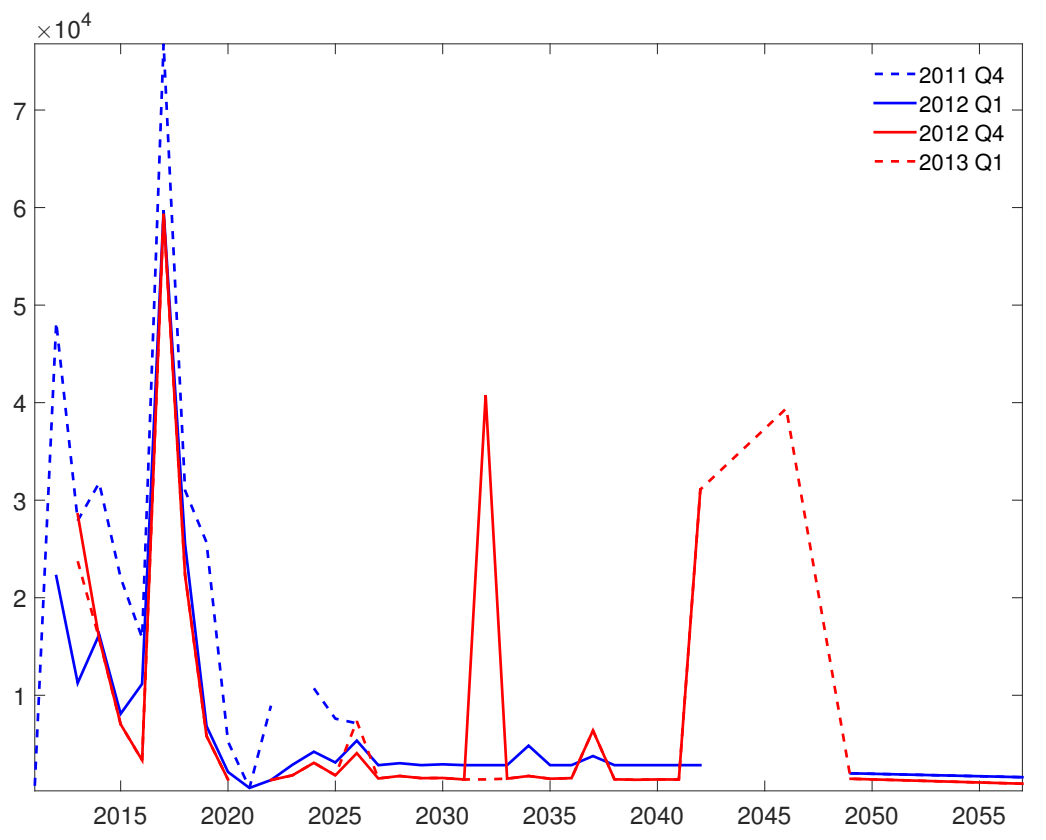

\begin{tabular}{lr}
\hline Quarter & Duration \\
\hline 2011 Q4 & 5.85 \\
2012 Q1 & 7.45 \\
2012 Q4 & 8.69 \\
2013 Q1 & 9.16 \\
\hline
\end{tabular}

Figure 8: External Debt for Greece, including official loans. Source: Bloomberg [2015] 


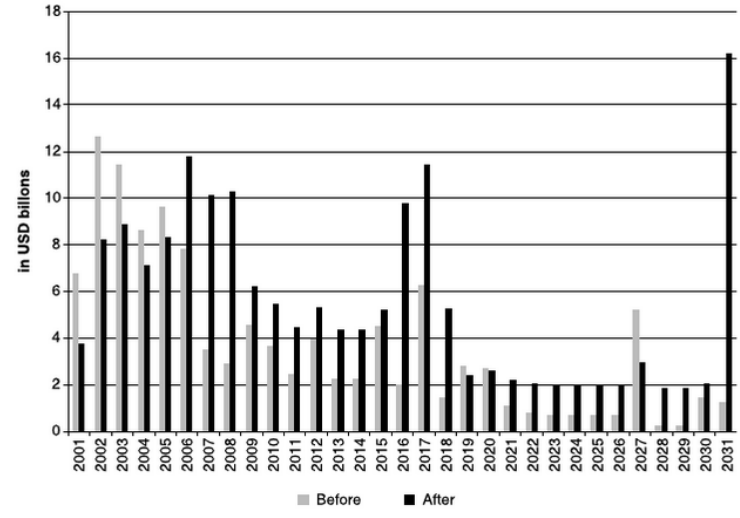

(a) Argentina 2005

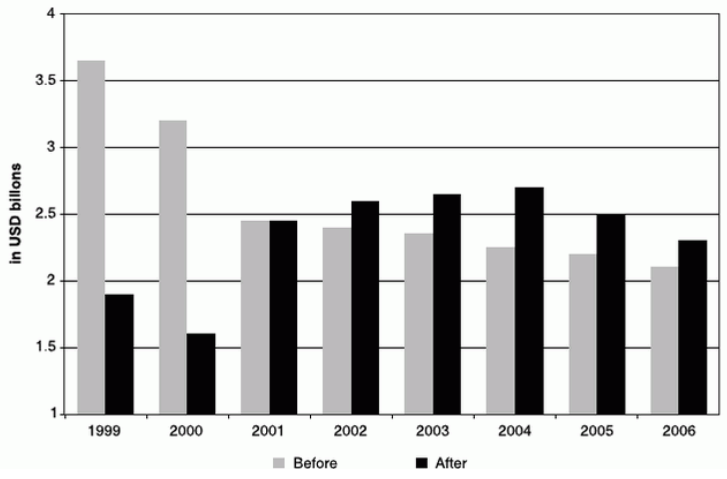

(c) Pakistan 1999

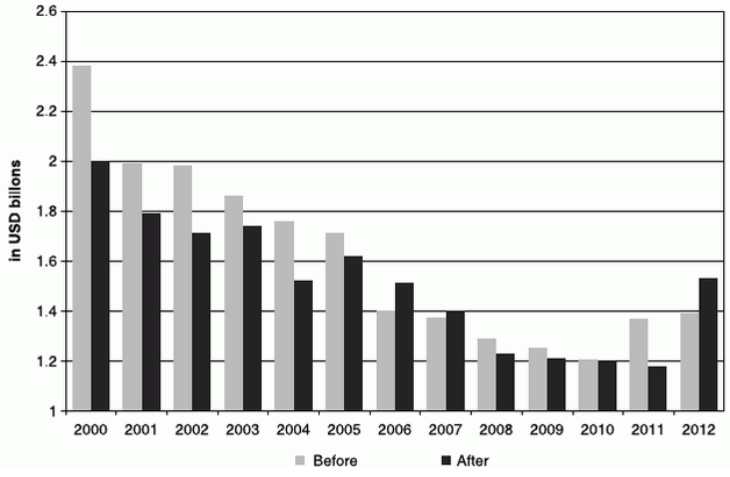

(b) Ecuador 2000

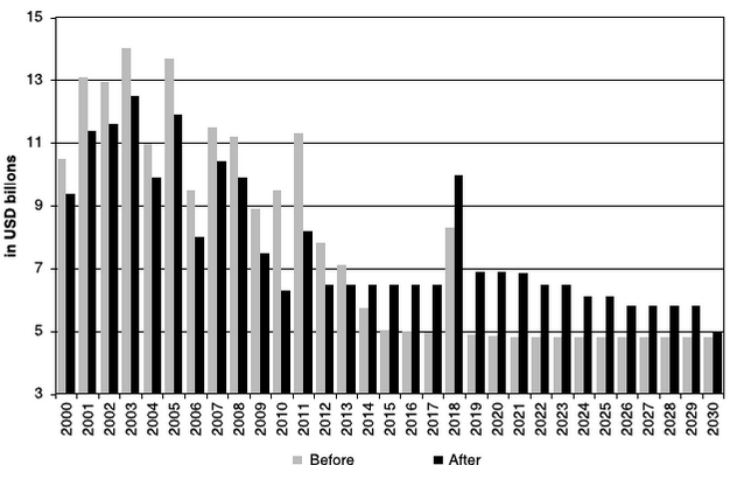

(d) Russia 2000

Figure 9: Cash flows, before and after debt swap, for additional events. Source: Sturzenegger and Zettelmeyer [2006] 